\title{
Fos After Single and Repeated Self-Administration of Cocaine and Saline in the Rat: Emphasis on the Basal Forebrain and Recalibration of Expression
}

\author{
Daniel S Zahm*,', Mary L Becker', Alexander J Freiman', Sara Strauch', Beth DeGarmo', Stefanie Geisler',3, \\ Gloria E Meredith ${ }^{2}$ and Michela Marinelli ${ }^{2}$
}

'Department of Pharmacological and Physiological Science, Saint Louis University School of Medicine, St Louis, MO, USA; '² Cellular and Molecular Pharmacology, The Rosalind Franklin University of Medicine and Science, North Chicago, IL, USA

\begin{abstract}
The effects of addictive psychostimulant drugs on the brain change over repeated administrations. We evaluated a large sample of brain structures, particularly ones comprising basal forebrain macrosystems, and determined in which the immediate-early gene product, Fos, is expressed following a single and repeated self-administrations of cocaine. The caudate-putamen and accumbens, comprising the basal ganglia input structures, and the hypothalamic supraoptic and paraventricular nuclei, lateral and medial habenula, mesopontine rostromedial tegmental nucleus and anterior cingulate cortex exhibited Fos expression enhanced by acute self-administration of cocaine (SAC), but desensitized after repeated administrations. Fos expression was mainly enhanced by acutely self-administered cocaine in basal ganglia output and intrinsic structures and the intermediate nucleus of lateral septum, medial division of the central amygdaloid nucleus and zona incerta, but, in contrast, was sensitized in these structures after repeated administrations. Acute and repeated SAC left Fos expression unaffected or marginally enhanced in most extended amygdala structures, of which nearly all, however, exhibited robustly increased Fos expression after repeated saline self-administration, occasionally to levels exceeding those elicited by cocaine. Thus, selfadministered cocaine mainly elicits Fos expression, which persists or increases with repeated administrations in some structures, but declines in others. In addition, Fos expression is sensitized in most extended amygdala structures merely by the act of repeated selfadministering. Similar spatiotemporal patterns of cocaine- or saline-elicited Fos expression characterize functionally related clusters of structures, such as, eg, basal ganglia input structures, basal ganglia output structures, extended amygdala and structures in the brainstem to which forebrain macrosystems project.

Neuropsychopharmacology (2010) 35, 445-463; doi:I0. I038/npp.2009. I49; published online 30 September 2009
\end{abstract}

Keywords: drug abuse; addiction; relapse; psychostimulant; dopamine

\section{INTRODUCTION}

Cocaine, a tenaciously addictive drug (de Wit and Stewart, 1981; Childress et al, 1988; O'Brien et al, 1990; Ehrman et al, 1992; Bauer and Kranzler, 1994; Bossert et al, 2005; O’Brien, 2005; Shaham and Hope, 2005), acts mainly by inhibiting the dopamine transporter (Koe, 1976; Ritz et al, 1987; Woolverton, 1987; Einhorn et al, 1988; Balster, 1990; Vanover et al. 1992; Howell and Byrd, 1995; Roberts et al, 1999; Wee and Woolverton, 2004), resulting in an accumulation of extracellular dopamine and consequent

*Correspondence: Professor DS Zahm, Department of Pharmacological and Physiological Science, St Louis University School of Medicine, I402 S. Grand Blvd, St Louis, MO 63104, USA, Tel: + 314977 8003, Fax: +31497764II, E-mail: zahmds@slu.edu

${ }^{3}$ Current address: Department of Neurology, Washington University School of Medicine, Box 8111, 660 S. Euclid Ave, Saint Louis, MO 63110, USA

Received I June 2009; revised 28 July 2009; accepted I8 August 2009 hyperstimulation of postsynaptic dopamine receptors. This, in turn, increases Fos expression preferentially in structures within the trajectory of the mesotelencephalic dopaminergic pathway (Graybiel et al, 1990; Young et al, 1991). Fos, encoded by the immediate-early gene, c-fos, contributes to transcriptional regulation of numerous macromolecules and is oft exploited to map neuronal activation (Curran and Morgan, 1985; Morgan and Curran, 1991; Sharp et al, 1993; Farivar et al. 2004).

Recently, Zhang et al (2006) showed that a conditional knockout of c-fos, preferentially targeted to postsynaptic D1 receptor-expressing neurons in the ventral and dorsal striatum, attenuates some of the behavioral and neurochemical effects of cocaine. Indeed, a number of other measures of neural activation, including glucose metabolism in rats (London et al, 1986; Porrino et al, 1988; Sharkey et al, 1991; Porrino, 1993; Macey et al, 2004), monkeys (Graham and Porrino, 1995; Lyons et al, 1996; Porrino et al, 2002), and humans (London et al, 1990), as well as cerebral blood flow 
in monkeys (Howell et al, 2002) and BOLD (blood oxygen level detection) signaling in humans (Breiter et al, 1997) indicate that the mesotelencephalic dopaminergic axis is engaged during acute cocaine administration, such that agents that attenuate neural activation within this axis should be expected to modulate the behavioral effects of cocaine. Accordingly, numerous investigations of cocaineelicited neuroadaptations that linger long after the cessation of drug use have focused on structures that receive dense dopaminergic input, such as the dorsal and ventral striatum (eg, Nestler, 2001a; b; 2005; 2008; LaRowe et al, 2007; Zavala et al, 2007; Conrad et al, 2008; Thomas et al, 2008; Moussawi et al, 2009). Similarly, most reports describing the effects of cocaine on Fos expression also contain observations limited to striatopallidum (eg, Graybiel et al, 1990; Hope et al, 1992; Cenci et al, 1992; Moratalla et al, 1993; ; Uslaner et al, 2001a; Crombag et al, 2002; Willuhn et al, 2003; Samaha et al, 2004).

However, the basal forebrain contains, in addition to striatopallidum, the extended amygdala and septal-preoptic projection system (Heimer, 2003; Heimer and Van Hoesen, 2006; Zahm, 2006; Heimer et al, 2008), which share fundamental neuroanatomical similarities with striatopallidum (Alheid and Heimer, 1988; Swanson, 2000; Zahm, 2006) and also receive substantial dopaminergic innervation (Fallon and Moore, 1978a; ; Fallon et al, 1978). Each is a potential substrate for neuroadaptation if it expresses cocaine-elicited Fos, particularly if in a manner that changes during a course of repeated cocaine administrations. Cocaine-elicited Fos expression has been reported in the extended amygdala (Day et al, 2001), as well as some other forebrain and brainstem structures, such as the subthalamic nucleus (Uslaner et al, 2001b; 2003) and rostromedial tegmental nucleus (Geisler et al, 2008; Jhou et al, 2009), that, interestingly, do not receive dense dopaminergic terminations. Furthermore, systemically and locally applied cocaine acutely modulates responses of cortical somatosensory neurons (Jimenez-Rivera and Waterhouse, 1991; Bekavac and Waterhouse 1995; Rutter et al, 1998; Drouin and Waterhouse, 2004) and cerebellar Purkinje cells (Jiménez-Rivera et al. 2000), both clearly beyond the reach of dopaminergic projections. Together, these considerations encourage casting the net beyond the striatum if the range of possible cocaine-induced neuroadaptations is to be adequately appreciated. One way to approach this is to better characterize the breadth of the collection of structures in which Fos expression is elicited by cocaine administration. Accordingly, we undertook to determine if Fos is expressed after acute and repeated self-administration of cocaine (SAC) in a select sample of brain structures, mostly representing different parts of the several basal forebrain macrosystems, and whether levels at which Fos is expressed after a single self-administration session are recalibrated after repeated administrations.

\section{MATERIALS AND METHODS}

Forty-five male Sprague-Dawley rats (Harlan, Indianapolis, IN) weighing $225-250 \mathrm{~g}$ entered the study, which was carried out in accordance with guidelines mandated in the National Institutes of Health Guide for the Care and Use of
Laboratory Animals. Twenty-five rats had been used in a previous study in which the retrograde tracer FluoroGold (FG) was injected unilaterally into the ventral tegmental area (VTA) at the time that rats were also instrumented with intra-jugular catheters for intravenous (i.v.) administration of cocaine or saline (see Geisler et al, 2008, for details). A second cohort of 20 rats that did not receive FG injections was instrumented with catheters at a subsequent time. All of the rats were singly housed on a $12 \mathrm{~h}$ reverse light-dark cycle and given food and water ad libitum. Unless stated otherwise, chemicals were purchased from Sigma (St Louis, MO).

\section{Implantation of Self-Administration Catheters}

The rats were deeply anesthetized by intraperitoneal injections of a cocktail consisting of $45 \%$ ketamine $(100 \mathrm{mg} / \mathrm{ml})$, $35 \%$ xylazine $(20 \mathrm{mg} / \mathrm{ml})$, and $20 \%$ saline at a dose of $0.16 \mathrm{ml} /$ $100 \mathrm{~g}$ of body weight. A silastic catheter ( $20 \mu \mathrm{l}$ dead volume) was inserted through the external jugular vein into the right atrium of the heart, passed under the skin and fixed in the midscapular region. As noted above, some of the rats also received iontophoretic injections of FG into one side of the mesencephalic VTA before awakening (see Geisler et al, 2008, for details). The rats were kept warm until they awakened and, thereafter, the catheters were flushed daily with sterile saline to prevent clogging.

\section{Self- and Investigator-Administration of Cocaine and Vehicle}

Seven to ten days after surgery, the animals were placed in selfadministration chambers (Med. Associates, St Albans, VT) and allowed to self-administer cocaine $(500 \mu \mathrm{g} / \mathrm{kg}$ per $30 \mu \mathrm{l}$ infusion) or saline for $2 \mathrm{~h} /$ day, during the dark part of the dark-light cycle, as previously described (Marinelli et al, 2003). Nose poking in an active hole delivered an infusion (cocaine or saline) and illuminated the hole with an LED light for $30 \mathrm{~s}$, whereas nose poking in an inactive hole had no programmed consequences. Self-administration was regarded as established when nose pokes were significantly more numerous in the active than inactive hole. During the self-administration period, a separate group of rats was placed in separate chambers located in the same environment as the self-administration chambers and given infusions of cocaine or saline, also by infusion pump, while the rats were held gently in the hand of the investigator. These investigator-administered infusions were given in numbers and at time intervals reflecting the averages delivered on the same day to the rats in the cocaine self-administering group. Patency of the catheters was confirmed with an infusion of $200 \mu \mathrm{l}$ of ketamine-xylazine mixture through the catheters on the last day of the experiment. All rats succumbed within 3-5 s following this treatment, indicating that all of the lines remained open throughout the study.

\section{Experimental Groups}

Groups, shown diagrammatically in Figure 1, comprised the following: a single session of saline (SAS 1 day; $n=6$ ) or cocaine (SAC 1 day; $n=6$ ) self-administration; self-administration of saline (SAS 6 days; $n=8$ ) or cocaine 


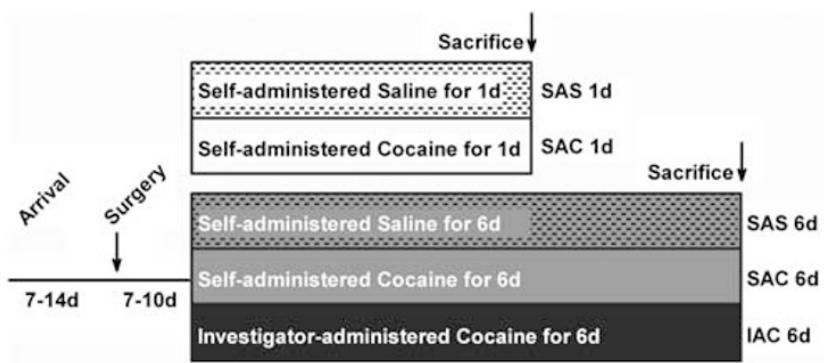

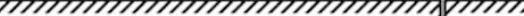
Self-administratered Saline or Cocaine for 5c 1d rest $\mathrm{d}$ basal Fos

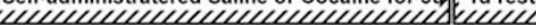

Figure I Diagram illustrating the experimental protocol and resulting groups. Abbreviations: d, days; h, hours; IAC, investigatoradministered cocaine; SAC, self-administered cocaine; SAS, self-administered saline.

(SAC 6 days; $n=9$ ) or investigator-administration of cocaine (IAC 6 days; $n=8$ ) in six consecutive daily sessions; and self-administration of cocaine $(n=4)$ or saline $(n=4)$ in five consecutive daily sessions with no infusion given on the sixth day (SAC 5 days and SAS 5 days, respectively). Rats were perfused $2 \mathrm{~h}$ following the start of the final drug or vehicle administration session, except for rats in the SAC 5 day and SAS 5 day (basal Fos) groups, which were anesthetized on the sixth day in the home cage and perfused immediately thereafter. Only rats in the 6 days cocaine (SAC 6 days and IAC 6 days) and vehicle (SAS 6 days) administration groups received VTA FG injections, which have been described separately (Geisler et al, 2008).

\section{Fixation of Brains and Immunocytochemistry}

Upon induction of deep anesthesia by an infusion of ketamine-xylazine mixture through the catheters, the rats were perfused transaortically with a solution of $0.1 \mathrm{M}$ Sorensen's phosphate buffer (SPB) containing 4\% freshly depolymerized paraformaldehyde $(\mathrm{pH} \quad 7.4)$ and $2.5 \%$ sucrose. The brains were removed, post-fixed in fresh fixative solution for $4 \mathrm{~h}$, rinsed in SPB, sunk in a $25 \%$ sucrose solution, and sectioned frozen on a sliding microtome. Five adjacent series of $50 \mu \mathrm{m}$ thick sections were collected, each representing an entire brain from frontal pole to caudal medulla. Each series of sections was stored in a separate glass vial at $-20^{\circ} \mathrm{C}$ in a cryoprotectant consisting of SPB containing 30\% sucrose and 30\% ethylene glycol. To promote uniform immunoreactions and minimize processing-related variability across the different cases, series of sections from rats in each of the various experimental groups were run 'in tandem', ie, immersed for identical times in aliquots of the immunohistochemical processing solutions. However, in tandem, ie, batch, processing of the 6 days SAS, SAC and IAC cohorts was carried out separately from that of the 1 day SAS, 1 day SAC, and basal Fos cohorts, because the self-administration sessions for the two sets of groups were run at different times.

Immunohistochemical processing steps were carried out at room temperature unless otherwise indicated, and under gentle agitation on a horizontal rotator (Lab-Line, Fisher, Pittsburgh, PA). As mentioned, for each step, several entire series of free-floating sections were processed in aliquots from batches of the relevant solutions. First, a rinse in $0.1 \mathrm{M}$ SPB ( $\mathrm{pH} 7.4$ ) was followed by immersion in $1 \%$ sodium borohydride for $15 \mathrm{~min}$ and subsequent thorough rinsing in $0.1 \mathrm{M}$ SPB. A brief pretreatment with $0.1 \mathrm{M} \mathrm{SPB}$ containing $0.2 \%$ Triton X-100 immediately followed, after which the sections were transferred into a solution of SPB containing $0.1 \%$ Triton X-100 (SPB-t) and a rabbit polyclonal antibody raised against a synthetic peptide corresponding to amino acids 4-17 of human c-Fos at a dilution of $1: 5000$ (Anti-cFos [Ab-5] [4-17] Rabbit pAb, formerly from Oncogene Science, Cambridge MA, now from Calbiochem, San Diego CA). The following day, after thorough rinsing in SPB-t, the various series of sections were immersed in aliquots of SPB$\mathrm{t}$ containing a biotinylated antibody against rabbit IgGs produced in donkey and used at a dilution of $1: 200$ (Jackson ImmunoResearch Laboratories, West Grove, PA) for an hour. Afterward, the sections were rinsed in SPB-t and then immersed in SPB containing avidin-biotinperoxidase complex $(\mathrm{ABC})$ at a dilution of $1: 200$ (Vector Laboratories, Burlingame, CA) for an hour. After thorough rinsing in $\mathrm{SPB}$, the sections were reacted in $0.025 \mathrm{M}$ Tris buffer ( $\mathrm{pH} 8.0$ ) containing $0.015 \% 3,3^{\prime}$-diaminobenzidine, $0.4 \%$ nickel ammonium sulfate, and $0.003 \%$ hydrogen peroxide, which generates an insoluble black reaction product. The sections then were rinsed and mounted onto gelatin-coated slides, dehydrated through a series of ascending concentrations of ethanol, transferred into xylene, and coverslipped with Permount (Fisher, Pittsburgh, $\mathrm{PA}$ ). Staining for Fos was absent when the primary or secondary antibodies or ABC reagents were omitted and following preabsorption with the cognate peptide (Calbiochem) used at a dilution of $50 \mathrm{ng} / \mu \mathrm{l}$.

\section{Immunofluorescence}

Series of sections from SAC 1-day brains were processed as described in the preceding subsection, but using the following sequence of immunoreagents: (1) rabbit anti-cFos (Calbiochem) used at a dilution of $1: 5000$ overnight, (2) biotinylated anti-rabbit from donkey (Jackson) used at $1: 200$ for $1 \mathrm{~h}$, (3) ExtrAvidin conjugated to fluorescein isothiocyanate (FITC, Sigma) used at 1:200 for $1 \mathrm{~h}$, mouse (monoclonal) anti-neuronal nuclear antigen (Chemicon, Temecula, CA), a marker of nearly all types of neurons in the vertebrate CNS (Mullen et al, 1992), used at 1:30000 overnight, and anti-mouse conjugated to Texas Red (Jackson) used at a dilution of $1: 100$ for $1 \mathrm{~h}$. The sections were mounted on subbed glass slides and coverslipped with ProLong Gold (Invitrogen, Eugene, OR). Sections were viewed and photographed with an Olympus BX51 light microscope in epifluorescence mode using a dual band filter block (Semrock, Rochester, NY - catalogue designation: FITC/TxRed-A, excitation centers (bandwidths) in $\mathrm{nm}$ : 479(38) and 585(27), emission centers(bandwidths) in $\mathrm{nm}$ : 534(29) and 628(33)). The relevant required excitation and emission values (provided by Semrock) are 492 and 520 (FITC) and 595 and 617 (Texas Red), respectively. Images were captured with a DVC-2000C digital camera and DVC View software (both DVC Company, Austin, TX). Red and green images in a single focal plane were acquired sequentially by tuning out non-relevant wavelength 
sensitivities with the software, which avoided shifts in the image and/or focal plane that accompany switching out filter blocks. For the purpose of illustration, magenta was substituted for red with Photoshop CS2 software (Adobe), after which merges were done with ImageJ software (NIH).

\section{Analysis of Fos-Ir Neuron Density}

Appropriate to the goal of establishing differences between groups in sectioned material identical in all respects other than numbers of Fos-expressing neurons, we chose to use density measurements (Saper, 1996) rather than stereological estimates (Coggeshall and Lekan, 1996) as the independent variable. This decision was in large part dictated by the large number of cases and structures requiring evaluation, which was carried out using a semiautomated approach described as follows. Sections were initially surveyed under brightfield optics with the aid of a Nikon Optiphot light microscope in brightfield mode at low magnification. Subjective estimates were made of the densities Fos-immunoreactive (ir) neurons in numerous structures in the brains of the saline self-administering controls (basal Fos and SAS 1 day and 6 day groups, see Table 1). Quantitative measurements of the density of Fos ir neurons in the corresponding SAS, SAC, and IAC groups were then recorded in a subset of these structures (within parentheses in Table 1). The quantitation was carried out by first identifying regions of interest (ROIs) at low magnification (Figure 2). The ROIs were then re-focused with the $\times 20$ objective, and digital images were captured using a Sony DXC-970MD video camera interfaced by means of an A-D converter to a dedicated software package (Northern Eclipse, Missisauga, ON) with the aid of which the digitized images were converted to gray scale, and densitometric thresholding was utilized to select optically dense Fos-ir nuclei. Thresholding was further refined by digitally rejecting detected objects too large or small to be Fos-ir nuclei. Selected Fos-ir nuclei also were pseudo-colorized, which allowed the evaluator to visually inspect the sample for undetected Fos-ir nuclei and objects detected by the software that should not have been. Either condition necessitated re-thresholding to optimize detection of Fosir nuclei. When this was achieved, the ROI was digitally circumscribed and the indicated area and number of detected objects within it were exported to a spreadsheet for calculation of object density and organization of the data for statistical analysis. In cases in which the ROIs did not approximate the entire field of view, the sizes and shapes of circumscribed ROIs were standardized across the six experimental groups. Measurements were recorded in quadruplicate, ie, in two sequential sections on both sides of the brain. Rarely, a missing section or section defect precluded acquisition of four measurements and the average was calculated instead with two or three. Group means were calculated and, using GB-STAT software (Dynamic Microsystems, Silver Spring, MD), statistically tested with a one-way ANOVA (density) followed as indicated by the LSD (least significant difference) post hoc test.
Table I Estimated Densities of Fos-ir Neurons in the Saline Control Groups

\begin{tabular}{|c|c|c|c|}
\hline & \multicolumn{3}{|c|}{ Fos-ir density ${ }^{a}$} \\
\hline & Basal & SAS I day & SAS 6 days \\
\hline \multicolumn{4}{|l|}{ Cortex } \\
\hline Frontal association & + & ++ & + \\
\hline Orbital & +++ & +++ & +++ \\
\hline (Piriform) & ++ & +++ & +++ \\
\hline (Prelimbic) & + & ++ & ++ \\
\hline Primary motor & ++ & ++ & ++ \\
\hline Granular insular & + & ++ & ++ \\
\hline (Anterior cingulate) & + & ++ & +++ \\
\hline (Primary somatosensory) & + & +++ & +++ \\
\hline Dysgranular insular & ++ & ++ & ++ \\
\hline Dorsal hippocampus & $\operatorname{tr}$ & + & + \\
\hline Ventral hippocampus & ND & ND & + \\
\hline Subiculum & ND & ND & ++ \\
\hline Granular retrosplenial & ++ & +++ & +++ \\
\hline Agranular retrosplenial & ++ & +++ & ++ \\
\hline Primary auditory & ++ & +++ & +++ \\
\hline Primary visual & ND & +++ & +++ \\
\hline Perirhinal & + & ++ & ++ \\
\hline Amygdalopiriform & ND & +++ & + \\
\hline Entorhinal & ND & +++ & + \\
\hline \multicolumn{4}{|l|}{ Basal forebrain } \\
\hline Anterior olfactory $n$ & ++ & +++ & +++ \\
\hline Dorsal endopiriform $n$ & + & ++ & + \\
\hline Olfactory tubercle & $\operatorname{tr}$ & + & + \\
\hline (Accumbens rostal pole) & + & ++ & ++ \\
\hline (Accumbens core) & + & ++ & ++ \\
\hline (Accumbens shell) & + & ++ & ++ \\
\hline Islands of Calleja & tr & + & + \\
\hline (Lateral septum, i) & + & + & + \\
\hline (Lateral septum, v) & + & ++ & ++ \\
\hline m septum-diagonal band & + & + & ++ \\
\hline (Caudate-putamen) & $\operatorname{tr}$ & ++ & + \\
\hline (entral pallidum) & $\operatorname{tr}$ & + & + \\
\hline (dl bed $n$ stria terminalis) & + & ++ & + \\
\hline ( $\mathrm{dm}$ bed $\mathrm{n}$ stria terminalis) & + & + & ++ \\
\hline ( $\vee$ bed $n$ stria terminal) & + & ++ & ++ \\
\hline (Globus pallidus) & 0 & $\operatorname{tr}$ & $\operatorname{tr}$ \\
\hline (Central $\mathrm{n}$ amygdala, l) & + & + & ++ \\
\hline (Central $\mathrm{n}$ amygdala, $\mathrm{m}$ ) & $\operatorname{tr}$ & + & ++ \\
\hline Basal $n$ amygdala & + & ++ & ++ \\
\hline Medial n amygdala & + & ++ & ++ \\
\hline \multicolumn{4}{|c|}{ Preoptic area and lateral hypothalamus } \\
\hline Lateral preoptic area & + & ++ & ++ \\
\hline Medial preoptic area & + & ++ & ++ \\
\hline (Suprachiasmatic n) & +++ & +++ & +++ \\
\hline (Supraoptic n) & + & ++ & + \\
\hline
\end{tabular}


Table I Continued

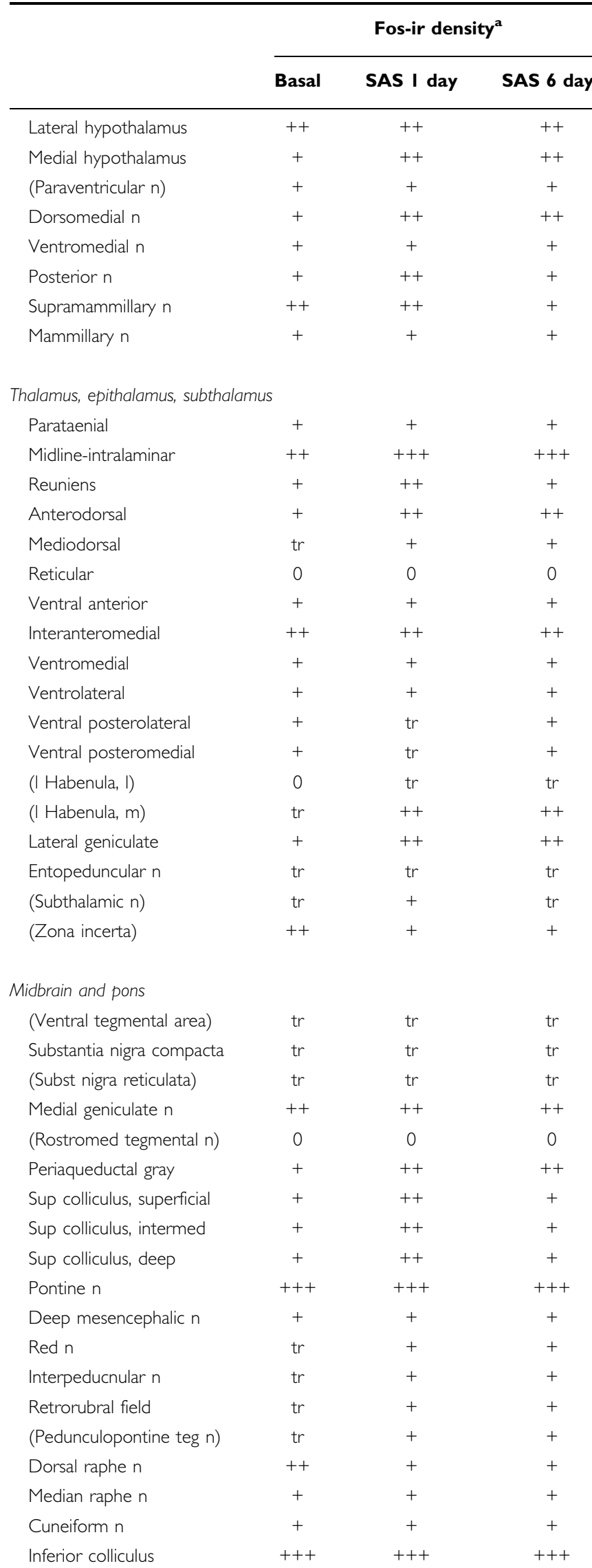

\begin{tabular}{|c|c|c|c|}
\hline & \multicolumn{3}{|c|}{ Fos-ir density ${ }^{a}$} \\
\hline & Basal & SAS I day & SAS 6 days \\
\hline Lateral lemniscus & + & + & + \\
\hline Pont retic $n$, oral & + & + & + \\
\hline (Laterodorsal tegmental $n$ ) & + & + & + \\
\hline Ventral tegmental $\mathrm{n}$ & ++ & ++ & ++ \\
\hline Dorsal tegmental $\mathrm{n}$ & ++ & ++ & ++ \\
\hline Parabrachial $n$ & + & + & ++ \\
\hline Trigeminal n, motor & $\mathrm{tr}$ & $\operatorname{tr}$ & + \\
\hline Trigeminal $n$, sensory & $\mathrm{tr}$ & + & + \\
\hline Superior olivary $n$ & 0 & + & + \\
\hline Locus ceruleus & 0 & + & + \\
\hline \multicolumn{4}{|l|}{ Medulla } \\
\hline Caud pontine reticular $n$ & tr & + & + \\
\hline Facial $n$ & $\operatorname{tr}$ & $\operatorname{tr}$ & $\operatorname{tr}$ \\
\hline Abducens $\mathrm{n}$ & 0 & $\operatorname{tr}$ & $\operatorname{tr}$ \\
\hline Medial vestibular $n$ & $\operatorname{tr}$ & + & + \\
\hline Cochlear $n$ & + & ++ & + \\
\hline Trigeminal $\mathrm{n}$, sensory & $\operatorname{tr}$ & $\operatorname{tr}$ & + \\
\hline Gigantocellular retic $n$ & tr & + & + \\
\hline Lateral reticular $n$ & $\operatorname{tr}$ & + & + \\
\hline n Prepositus & $\operatorname{tr}$ & + & + \\
\hline $\mathrm{n}$ Tracts solitarius & $\operatorname{tr}$ & + & + \\
\hline n Ambiguous & $\operatorname{tr}$ & + & + \\
\hline Dorsal motor $n$ vagus & $\operatorname{tr}$ & $\operatorname{tr}$ & + \\
\hline Hypoglossal n & tr & $\operatorname{tr}$ & + \\
\hline Medullary dorsal horn & $\operatorname{tr}$ & + & ++ \\
\hline \multicolumn{4}{|l|}{ Cerebellum } \\
\hline Granule cells & +++ & +++ & +++ \\
\hline Deep nn & $\mathrm{tr}$ & $\operatorname{tr}$ & $\operatorname{tr}$ \\
\hline
\end{tabular}

${ }^{a}$ Table entries reflect the averages of three cases, which were computed by assigning observations of $0,0-10,11-75,76-200$, and more than 200 Fos-ir nuclei/20x field numerical values of $0,0.5,1,2$, and 3 . Averages of 0 and in the ranges of $0.01-0.66,0.67-1.44,1.45-2.22$, and $2.23-3$ are listed in the table as 0 , $\operatorname{tr}$ (trace),,+++ , and +++ , respectively. Entries in parentheses were subjected to additional objective analysis illustrated in Figures 5-8 and Table 2. $\mathrm{dl}$, dorsolateral; dm, dorsomedial; I, intermediate; ir, immunoreactive; I, lateral; m- medial; n, nucleus; ND, not determined; nn, nuclei; retic, reticularis; rostromed, rostromedial; subst, substantia; sup, superior; teg, tegmental; $\checkmark$, ventral.

\section{A Note on the ROIs}

The ROIs shown in Figure 2 were selected both to represent a relatively broad sample of brain structures, with an emphasis on forebrain macrosystems, and test whether Fos expression elicited by SAS and SAC differs in different subdivisions of the same structures, such as, eg, accumbens core, shell and rostral pole (Figure 2a and b), central and ventrolateral parts of the caudate-putamen (Figure 2d), dorsolateral, dorsomedial and ventral divisions of the bed nucleus of stria terminalis (Figure $2 \mathrm{~h}$ ), medial and lateral 


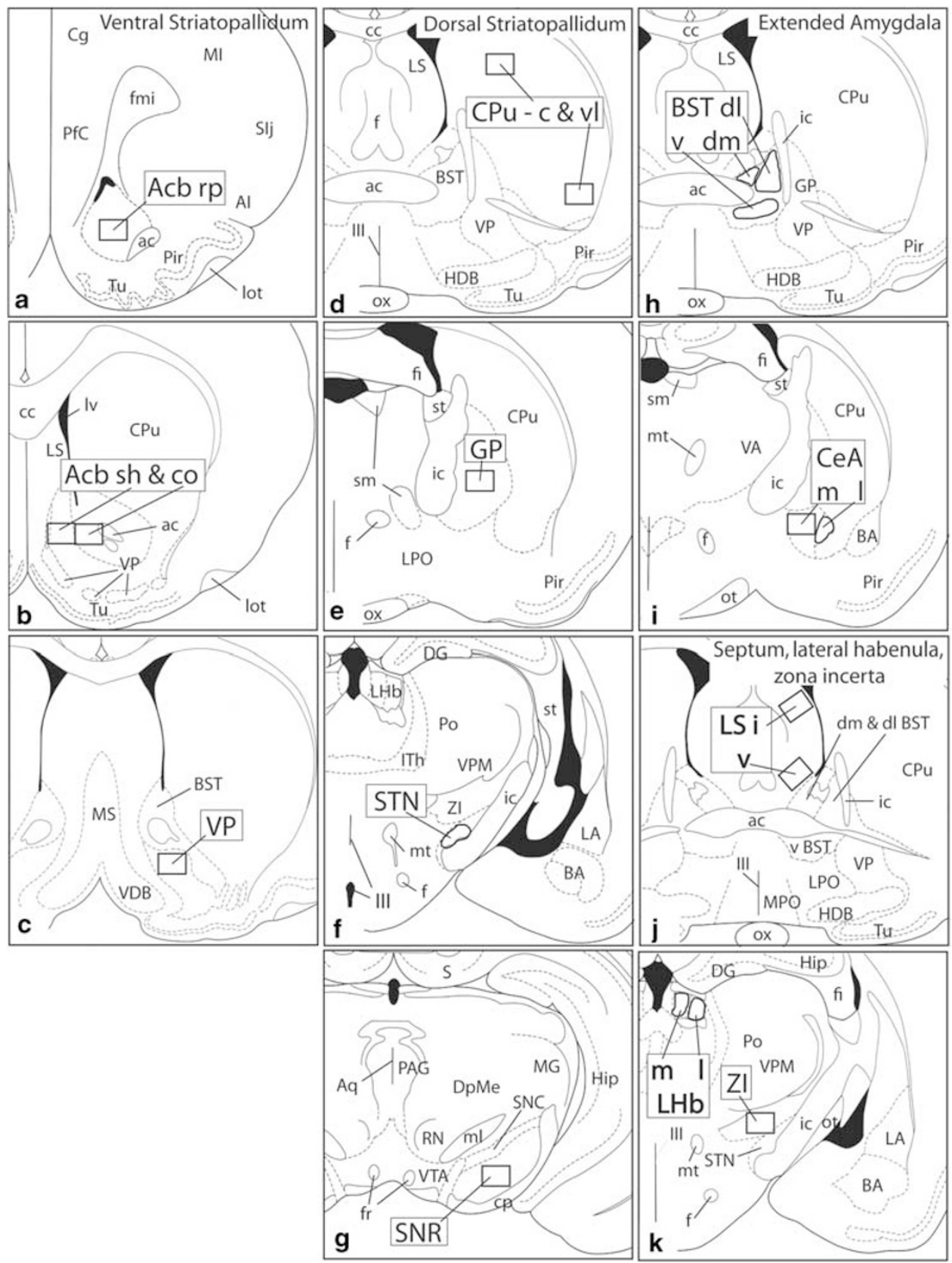

Figure 2 Diagrams illustrating the 32 regions of interest (ROIs) subjected to computer-assisted counting in this study (a-t). ROls are shown as boldly outlined rectangles or irregularly shaped areas, labeled with large, bold font, that conform to the size and shapes of the areas actually evaluated. ac, anterior commissure; Acb, accumbens; Al, agranular insular cortex; aq, cerebral acqueduct; BST, bed nucleus of stria terminalis; cc, corpus callosum; c, central division; BA, basal amygdaloid nucleus; Cbl, cerebellum; CeA, central nucleus of the amygdala; Cg, anterior cingulate cortex; co, core; cp, cerebral peduncle; Cpu, caudate-putamen; DG, dentate gyrus; dl, dorsolateral division; dm, dorsomedial division; DpMe, deep mesencephalic nucleus; f, fornix; fi, fimbria fornix; FL $\mathrm{HL}$, primary somatosensory cortex, forelimb/hindlimb area; fr, fasciculus retroflexus; GP, globus pallidus; Hip, hippocampus; HDB, horizontal limb of the diagonal band; I, intermediate division; ic, internal capsule; IPN, interpeduncular nucleus; Ith, intralaminar nuclei of the thalamus; I, lateral division; LA, lateral nucleus of the amygdala; Ifp, longitudinal fasciculus of the pons; LHb, lateral habenula; LS, lateral septum; lot, lateral olfactory tract; LPO, lateral preoptic area; Iv, lateral ventricle; m, medial division; mcp, medial cerebellar peduncle; MG, medial geniculate body; Ml, first primary motor cortex; ml, medial lemniscus; mIf, medial longitundinal fasciculus; MnR, median raphe; MPO, medial preoptic area; MS, medial septum; mt, mammillothalamic tract; ot, optic tract; ox, optic chiasm; PAG, periacqeductal gray; PfC, prefrontal cortex; Pir, piriform cortex; Po, posterior nucleus of the thalamus; PPTg, pedunculopontine tegmental nucleus; PrL, prelimbic cortex; py, medullary pyramid; RMTg, rostromedial tegmental nucleus; RN, red nucleus; rp, rostral pole; RRF, retrorubral field; sh, shell; Slj, primary somatosensory cortex, jaw area; sm, stria medullaris; SNC, substantia nigra compacta; SNR, substantia nigra reticulata; spc, superior cerebellar peduncle; st, stria terminalis; STN, subthalamic nucleus; Tu, olfactory tubercle; $v$, ventral division; $V$, trigeminal nerve; $V A$, ventral anterior nucleus of the thalamus; VDB, vertical limb of the diagonal band; vl, ventrolateral division; VP, ventral pallidum; VPM, ventral posteromedial thalamic nucleus; VTA, ventral tegmental area; xscp, crossing of the superior cerebellar peduncle; ZI, zona incerta; II, optic tract; III, third ventricle; IV, fourth ventricle. 

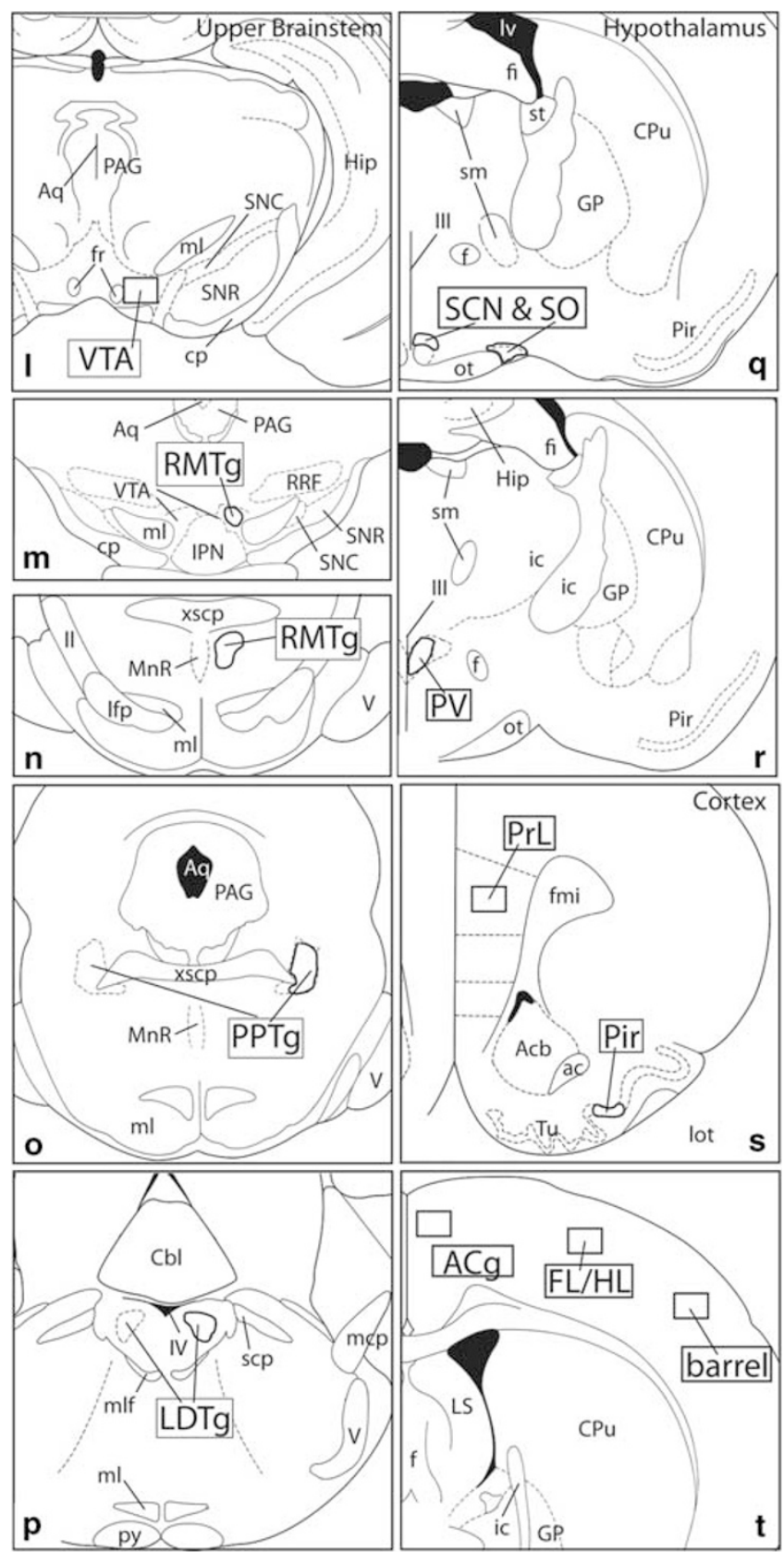

Figure 2 (continued)

divisions of the central amygdaloid nucleus (Figure 2i), intermediate and ventral divisions of the lateral septal nucleus (Figure 2j), medial and lateral divisions of the lateral habenular nucleus (Figure $2 \mathrm{k}$ ), and rostral and caudal parts of the rostromedial tegmental nucleus (Figure $2 \mathrm{~m}$ and $\mathrm{n}$ ).

Certain of the ROIs require a sentence or two in further explanation. The rostromedial tegmental nucleus is a recently described structure in the ventral mesencephalon comprising a rostral part (RMTg r; Figure $2 \mathrm{~m}$ ), which is embedded among the dopaminergic processes of the caudomedial VTA, and caudal part (RMTg c, Figure 2n), which occupies the medial tegmentum caudal to the VTA. Both parts of the RMTg exhibit strong Fos expression in the cocaine-exposed brains (Geisler et al, 2008; Jhou et al, 2009). The ROI for the suprachiasmatic nucleus (SCN) comprises not the SCN itself, but rather a Fos-dense cap region suprajacent to it (Figure 2q). The ROI for the piriform cortex (Figure 2s) includes only the dense cell layer. ROIs for the $\mathrm{S} 1$ cortex (Figure 2t) correspond to the Fos-dense lamina 3.

\section{RESULTS}

\section{Behavior}

Rats in the SAC 1 day, SAC 6 day, and IAC 6 day groups received about the same number of cocaine infusions in all sessions (Figure 3a), indicating that the rats in each of these groups on average had similar amounts of cocaine on-board on day of killing and that the self-administration history for the SAC 6 day and IAC 6 day rats was on average similar. However, as indicated in Figure $3 b$ and $c$, responding (numbers of nose pokes) and locomotor activity, respectively, declined over several daily sessions in the SAC 6 day group to values significantly below the mean of the SAC 1 day group, likely reflecting the tendency of SAC 6 day rats to make fewer ineffective approaches and nose pokes as they accumulate experience in self-administering. SAS rats were about half as active and delivered about $35 \%$ of the infusions recorded for SAC rats. However, responding and locomotor activity in the SAS 6 day group were comparable with that of SAS 1 day rats throughout the course of six consecutive self-administration sessions.

Some rats in the group that self-administered cocaine for 5 days and was anesthetized in the home cage on day 6 (SAC 5 days 'basal Fos' group) delivered lesser amounts of cocaine than did rats in the SAC 1 and 6 day groups (Figure 3a). Two such rats actually stopped self-administering on days 4 and 5. Despite these drug intake anomalies, uniformly low Fos expression was detected in all of the 'basal Fos' rats, whether SAS or SAC and whether they discontinued self-administering or persisted through the full 5 days (see below).

\section{Fos Immunoreactivity}

Immunoreaction product generated with the Fos antibody occupied exclusively cell nuclei (Figures 4, 5, 10 and 11). The impression that such immunolabeled nuclei represented a range of sizes consistent with mainly neuronal labeling was confirmed with immunofluorescence doublelabeling with the neuron-specific marker NeuN (Mullen et al, 1992) in sections from SAC 1 day brains, which revealed in several structures, including the accumbens, caudate-putamen (Figure 4), and piriform cortex, that Fosir nuclei were confined almost exclusively to NeuN ir profiles. Fos labeling was present in many brain structures in densities that varied depending on the treatment group (Table 1; Figures 6-9).

\section{Saline Controls}

SAS 1 day (Figure $5 a$ and $b$ ) and 6 day (Figure $5 c$ and d) brains exhibited abundant and widespread Fos-ir nuclei in numerous brain structures, whereas fewer and more 
lightly immunostained Fos-ir nuclei were present in the brains of rats that self-administered cocaine (SAC 5 days) or saline (SAS 5 days) on 5 consecutive days and then were anesthetized in the home cage on day 6 and killed immediately thereafter (Figure $5 \mathrm{e}$ and $\mathrm{f}$, Table 1). The estimated relative densities of Fos-ir cells in the saline and basal Fos groups are shown in Table 1. Estimates given in Table 1 were validated by objective quantitation in 32 structures (within parentheses in Table 1) that were selected as ROIs for quantitative analysis. The ROIs (Figure 2) are described in the Materials and Methods section.

\section{Quantitative Comparisons}

Fos labeling, expressed as mean density of Fos-ir neuronal nuclei in ROIs after 1 session and 6 consecutive daily sessions of SAC or SAS, is shown in Figures 6-9, where saline controls (SAS) are paired with the directly comparable cocaine-receiving (SAC and IAC) groups. Each ROI (Figure 2) is represented by a cluster of five vertical bars and a horizontal reference for 'basal Fos' expression. Acute groups are represented by a pair of bars: SAS (1 day, $n=6$, white bars with hatches) and SAC (1 day, $n=6$, white bars). Repeated administration groups are represented by 3 bars: SAS ( 6 day, $n=8$, gray bars with hatches), SAC ( 6 day, $n=9$, gray bars), and IAC ( 6 day, $\mathrm{n}=8$, black bars). Widths of the horizontal bars reflect the magnitude of the SEM above and below the mean for 'basal Fos' expression. As noted above, because significant differences were not detected between the basal SAC and basal SAS groups, the data from those groups were pooled. The results of the ANOVA and LSD post hoc tests applied to the data are given in the cross-reference tables beneath the graphs (Figures $6 c-8 c$ and $9 b$ ) and in Table 2. Table 2 shows, in addition, the actual magnitudes of significant responses, reflected in the mean SAC and 1 day values after the respective SAS and 6 day means were subtracted out.

$S A C$ vs SAS. Cocaine, whether self-administered over 1 or 6 sessions or administered by the investigator over 6 sessions, mainly increased Fos expression as compared with the relevant SAS group (Figures 6-9; Table 2, column A). Two different kinds of response could be observed. In one, Fos expression was low in the SAS group (Figure 10a, b, e and f) and much greater in the corresponding SAC group (Figure $10 \mathrm{c}, \mathrm{d}, \mathrm{g}$ and $\mathrm{h}$ ) after both 1 and 6 self-administration sessions, resulting in marked increases in both the intensity of immunostaining of Fos-ir/nucleus and density of Fos-ir neurons. Evaluated structures exhibiting this type of response included the ventral pallidum (Figure 6a), caudate-putamen (Figures $6 \mathrm{~b}$ and 10), globus pallidus (Figure 6b), subthalamic nucleus (Figure 6b), substantia nigra reticulata (Figure 6b), intermediate division of the lateral septum (Figure $7 \mathrm{~b}$ ), lateral division of the lateral habenula (Figure 7b), zona incerta (Figure 7b), VTA (Figure 8a), and rostromedial tegmental nucleus (Figure 8a). The other response type was reflected in moderate amounts of SAS-elicited Fos labeling that could be moderately greater in the corresponding SAC groups, after either 1 or 6 self-administration session(s), but generally not both. Structures exhibiting this kind of response after 1 , but not 6 , session(s) included the accumbens rostral pole (Figure 6a), dorsomedial division of the bed nucleus of stria terminalis (Figure 7a), medial division of the lateral habenula (Figure 7b), supraoptic nucleus (Figure 8b), and prelimbic and anterior cingulate cortex (Figure 9). Structures that exhibited this response after 6 , but not 1 , sessions included the dorsolateral division of the bed nucleus of stria terminalis (Figure 7a) and the pedunculopontine and laterodorsal tegmental nuclei (Figure 8a).

Three (of 32) quantitatively evaluated structures - the lateral division of the central amygdaloid nucleus (Figure $6 c$ ), ventral division of the lateral septum (Figure $7 \mathrm{~b}$ ), and supraoptic nucleus (Figure $8 \mathrm{~b}$ ) — exhibited a significantly lesser density of Fos-ir nuclei following cocaine administration as compared with the corresponding SAS group after 6, but not 1, self-administration sessions. Interestingly, of these, the lateral division of the central amygdaloid nucleus and supraoptic nucleus exhibited greater than control Fos expression after the first cocaine self-administration session. Note, however, that the apparent decreases in SAC Fosexpressing neurons in the lateral division of the central amygdaloid nucleus and ventral division of the lateral septum on day 6 were due not to fewer SAC-elicited Fosexpressing neurons, but rather to greatly increased SASelicited Fos expression (Figure 7a and b; Table 2). In contrast, the change in density of Fos-expressing neurons between day 1 and day 6 in the supraoptic nucleus reflected a true decrease in the numbers of Fos-expressing neurons (Figure $8 \mathrm{~b}$ and Table 2). No significant differences distinguishing SAS and SAC groups at 1 or 6 days were observed in the accumbens shell or core (Figure 11), piriform cortex, forelimb/hindlimb somatosensory cortex, or SCN.

Day 6 vs Day 1. Table 2, column B shows that the density of Fos-ir neurons after 6 daily sessions of cocaine
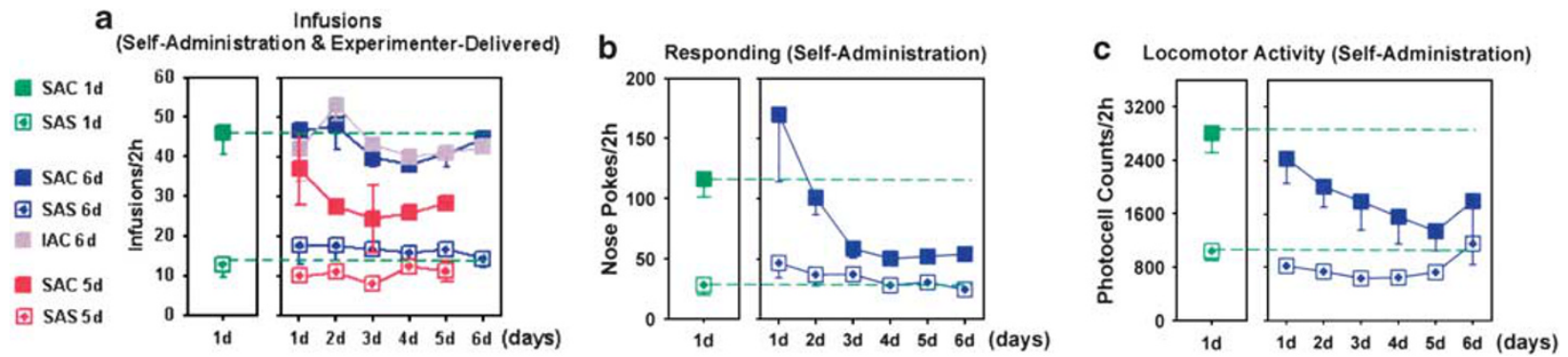

Figure 3 Diagrams illustrating the behavior of the rats used in the study in terms of numbers of cocaine and saline infusions (a), numbers of responses (b) and (c) locomotor activity. Means and SEMs are shown. 

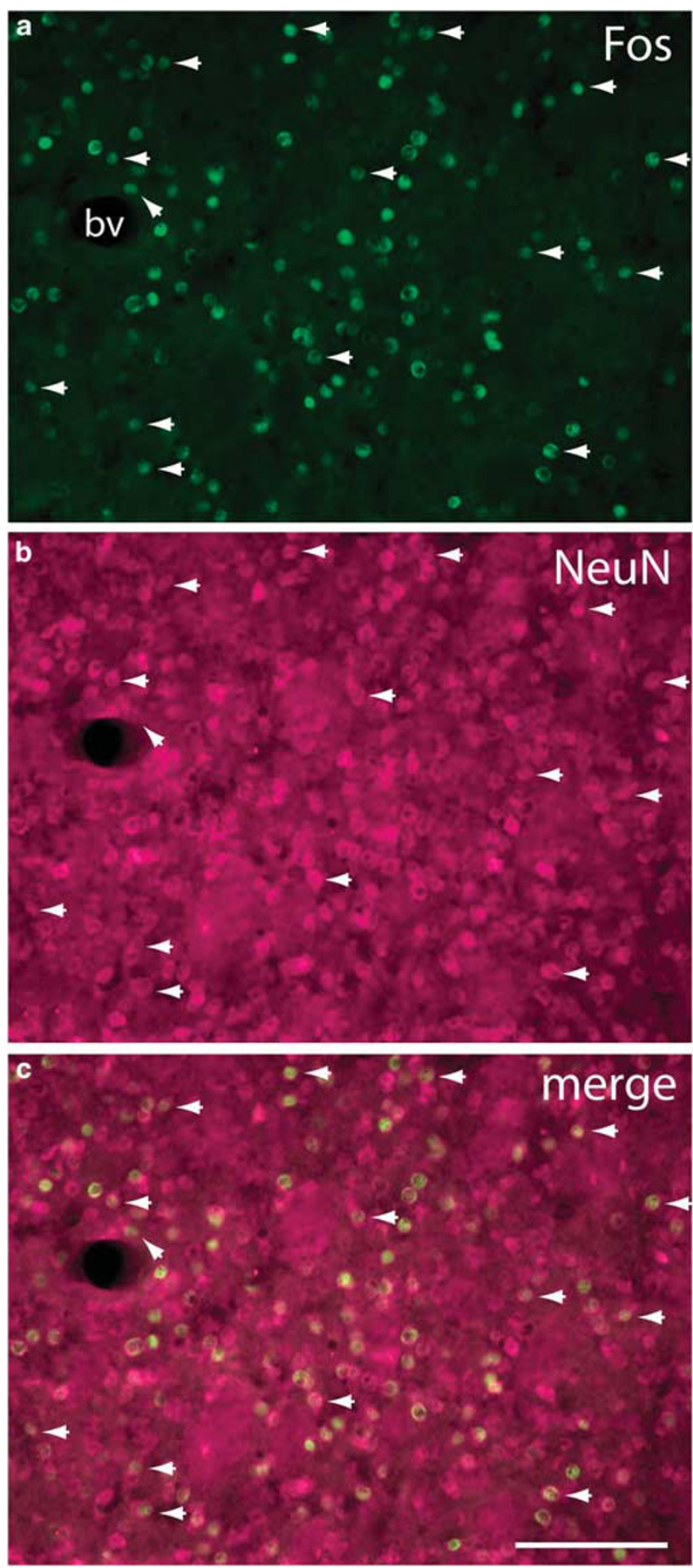

Figure 4 Fluorescence micrographs of the central caudate-putamen (see Figure 2d) of an SAC I day rat illustrating localization of Fos-immunoreactive nuclei (a) within cells identified in panel (b) as neurons on the basis of immunoreactivity against the neuronal nuclear antigen (NeuN). An obliquely oriented arrowhead near a blood vessel (bv) marks the only Fos immunoreactive structure in the field not colocalized with a NeuN immunoreactive structure. Horizontally oriented arrowheads mark examples illustrating that $\mathrm{NeuN}$ immunoreactive structures, because $\mathrm{NeuN}$ often stains both the cell body and nucleus, are usually larger than the colocalized Foslabeling. The disparity in the size and shape of co-localized Fos- and NeuNimmunoreactive structures, also apparent in the merged image (c) rules out the possibility that the near complete assocation of Fos-ir nuclei with NeuN structures is due to bleed-through of the FITC signal. Scale bar. $100 \mu \mathrm{m}$.
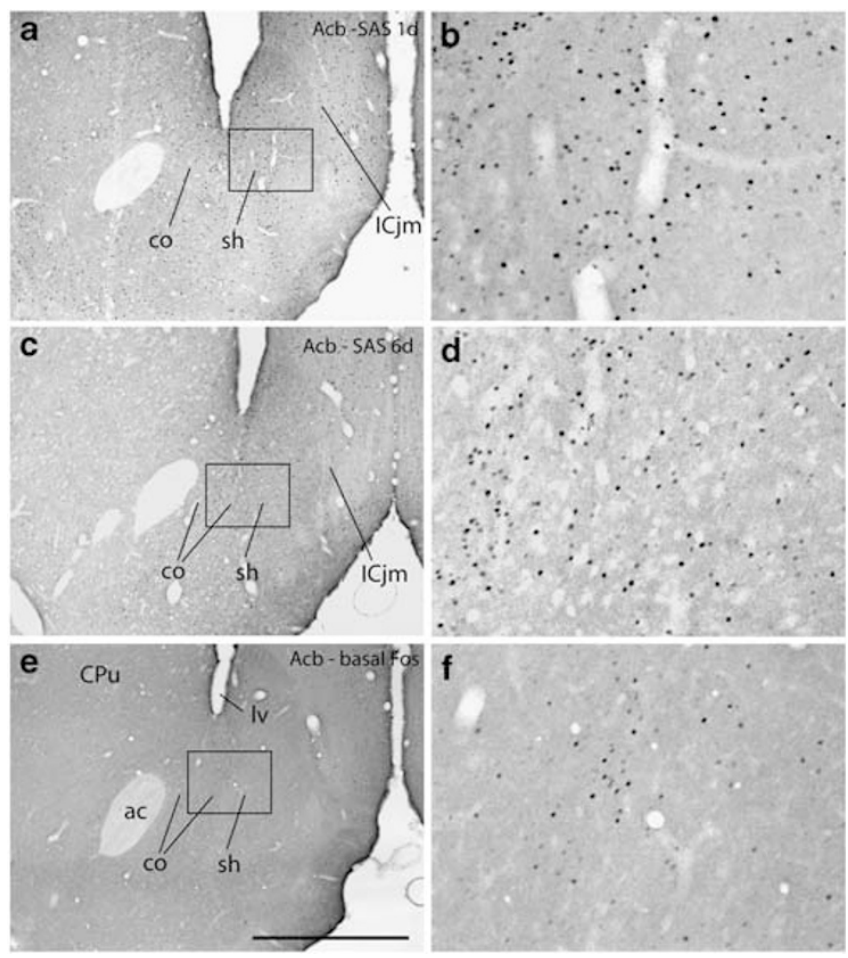

Figure 5 Photomicrographs illustrating Fos immunoreactive neurons in the accumbens (Acb) in the I (I day) and 6 (6 day) day saline selfadministration (SAS) groups and in the basal Fos expression group, which comprised rats that self-administered saline for 5 days and were killed on the sixth day with no further opportunity to self administer. b, d, and e are enlargements of the boxed areas in a, c, and e, respectively. co, Acb core; sh, Acb shell; ICjm, Island of Calleja magnus; Iv, lateral ventricle. Scale bar: I $\mathrm{mm}$ in a, c, and e; $200 \mu \mathrm{m}$ in b, d, and $\mathrm{f}$.

self-administration differed significantly in a number of brain structures from that observed in the same structures following only 1 self-administration session. The same column, in addition, provides the actual magnitudes of significant responses, reflected in the mean day 6 values after the respective day 1 means had been subtracted out. Structures in which Fos-ir neuron density was greater after 6 sessions as compared with 1 included the ventral pallidum (Figure 6a), globus pallidus (Figure 6b), substantia nigra pars reticulata (Figure 6b), dorsolateral and ventral divisions of the bed nucleus of stria terminalis (Figure 7a), lateral division of the central amygdaloid nucleus (Figure 7a), intermediate division of the lateral septum (Figure 7b), zona incerta (Figure 7b), and VTA (Figure 8a). Structures in which Fos-ir neuronal density decreased after 6 sessions as compared with 1 included the accumbens rostral pole and shell (Figure 6a), central and ventrolateral parts of caudate-putamen (Figure 6b), medial and lateral divisions of the lateral habenula (Figure $7 \mathrm{~b}$ ), rostral and caudal parts of the rostromedial tegmental nucleus (Figure 8a), hypothalamic supraoptic and paraventricular nuclei (Figure 8b), and anterior cingulate cortex (Figure 9). Fos-ir neuron density in the SAS group was increased in a number of structures after 6 as compared with 1 sessions. These included the dorsomedial and ventral divisions of the bed nucleus of stria terminalis (Figure 7a), medial and 

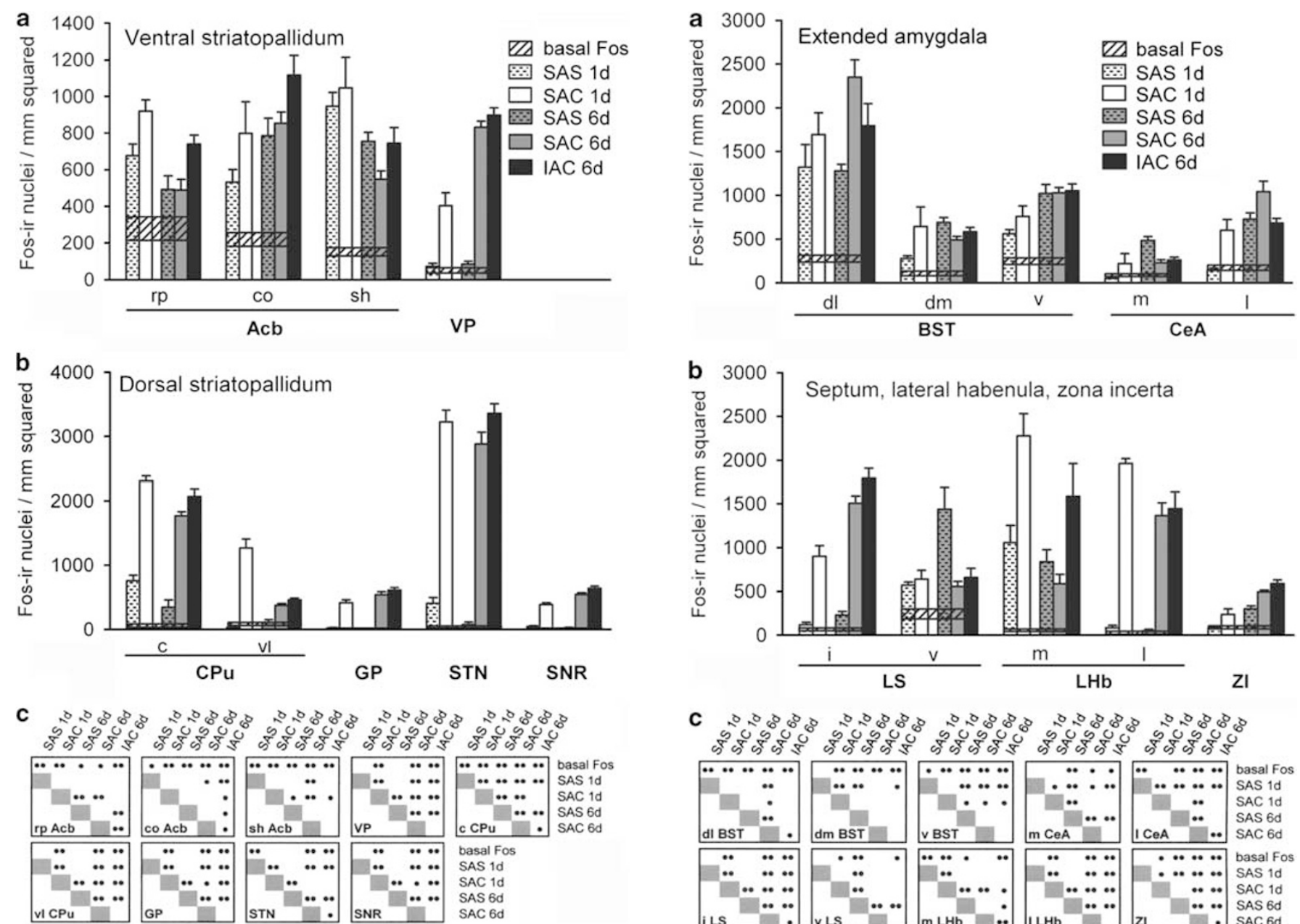

Figure 6 Graphs illustrating the density of Fos-immunoreactive nuclei in the ventral striatopallidum (a), including the accumbens (Acb) and ventral pallidum (VP), and dorsal striatopallidum (b), including the caudate-putamen $(\mathrm{CPu})$, globus pallidus (GP), subthalamic nucleus (STN), and substantia nigra reticulata (SNR), for the experimental groups as described in the text. Means and SEMs are shown (c) Cross-referenced results of ANOVA and LSD post hoc tests. $\bullet p<0.05 ; \bullet \bullet p<0.0$ I. Widths of the horizontal bars reflect the magnitude of the SEM above and below the mean for 'basal Fos' expression. c, central division of CPu; co, Acb core; IAC, investigatoradministered cocaine; $r p$ Acb, rostral pole; SAC, self-administered cocaine; SAS, self-administered saline; shvAcb, shell; vl, ventrolateral division of CPu.

lateral divisions of the central amygdaloid nucleus (Figure 7a), ventral division of the lateral septum (Figure $7 b$ ), zona incerta (Figure $7 b$ ), and piriform cortex (Figure 9). Fos-ir neuron density decreased after 6 as compared with 1 saline self-administration sessions in the central part of the caudate nucleus (Figure 6a), laterodorsal tegmental nucleus (Figure 8a), supraoptic nucleus (Figure 8b), and the somatosensory cortical barrel field (Figure 9).

Patterns of Fos Response. One subset of evaluated structures exhibited negligible Fos expression following SAS, but robust Fos expression after both 1 session and 6 consecutive daily sessions of cocaine administration. Another group of evaluated structures exhibited moderate to robust expression of Fos following SAS and many of

these showed a further, generally modest, augmentation of Fos expression, after either 1 or 6 sessions of cocaine selfadministration. The different Fos responses were not randomly distributed among basal forebrain and brainstem structures, but instead clustered in patterns reflecting the identities of various components of basal forebrain macrosystems (Table 2).

Thus, evaluated basal ganglia input nuclei, which include subterritories of the accumbens and caudate-putamen, adhered to a general pattern in which cocaine mainly enhances Fos expression in a robust manner that desensitizes after repeated administrations. Fos expression in these structures was greater or statistically similar in the SAC as compared with SAS condition on days 1 and 6 , while SAC-elicited Fos expression after 6 sessions as compared with 1 session was mainly decreased. SAS-elicited 

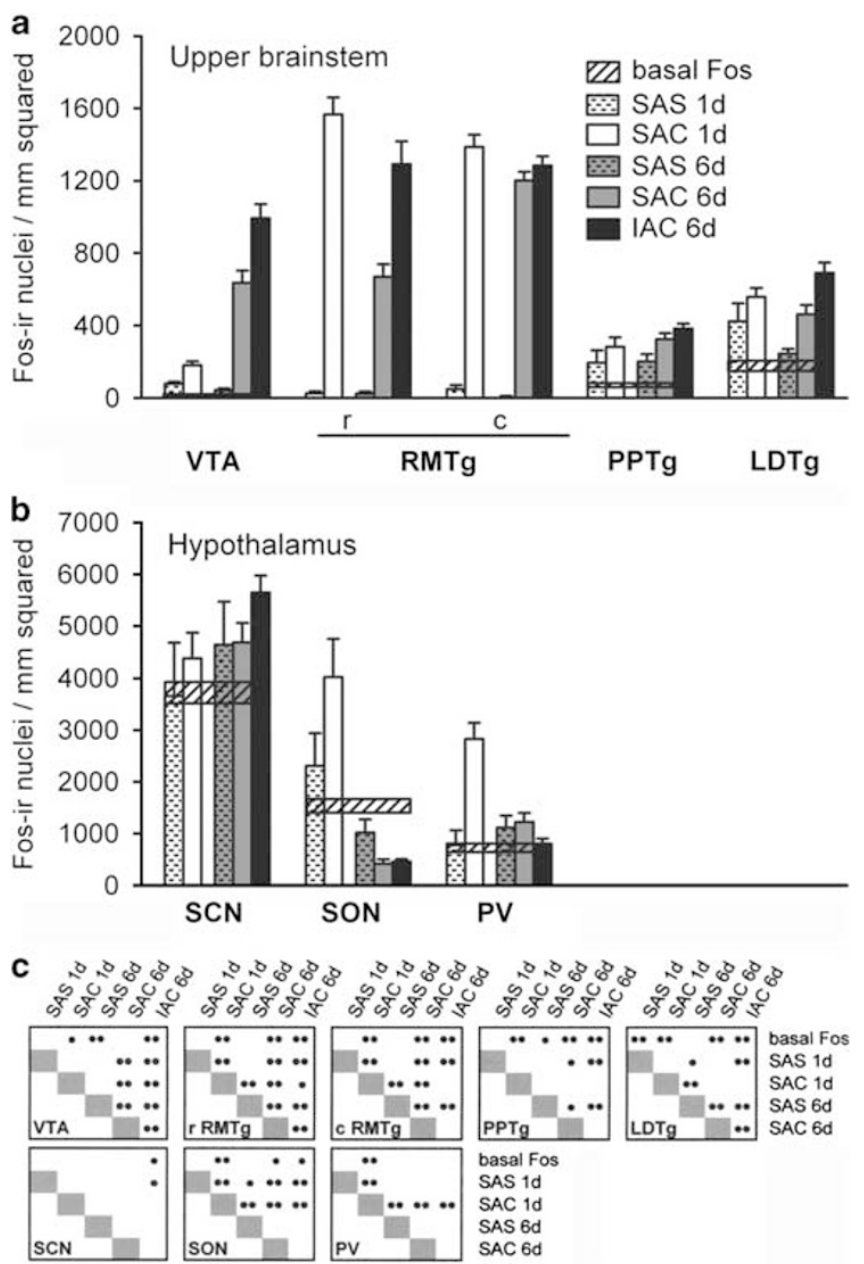

Figure 8 Graphs illustrating the density of Fos-immunoreactive nuclei in some structures in the upper brainstem (a), including the ventral tegmental area (VTA), rostromedial tegmental nucleus (RMTg), and pedunculopontine (PPTg) and laterodorsal (LDTg) tegmental nuclei, and in the hypothalamus (b), including the suprchiasmatic nucleus ( $\mathrm{SCN}$ ), supraoptic nucleus (SON) and paraventricular nucleus (PV), for the experimental groups as described in the text. Conventions in $(\mathrm{a}-\mathrm{c})$ are as in Figure 6. c, caudal division; IACV, investigator-administered cocaine; $\mathrm{r}$, rostral division; SAC, self-administered cocaine; SAS, self-administered saline.

Fos expression after 6 sessions as compared with 1 session was mainly unchanged in these structures. This pattern, ie, acute cocaine-elicited robust enhancement of Fos expression that desensitizes on repeated administrations, was also observed in the lateral habenula, rostromedial tegmental nuclei, pedunculopontine and laterodorsal tegmental nucleus, hypothalamic paraventricular and supraoptic nuclei, and anterior cingulate and barrel field cortex.

In evaluated basal ganglia output and intrinsic nuclei, including the ventral pallidum, globus pallidus, subthalamic nucleus, substantia nigra reticulata, and VTA, and also in the intermediate division of the lateral septum, lateral division of the central amygdaloid nucleus, and zona incerta, SAC as compared with SAS on days 1 and 6 was accompanied by robustly increased Fos expression. In all
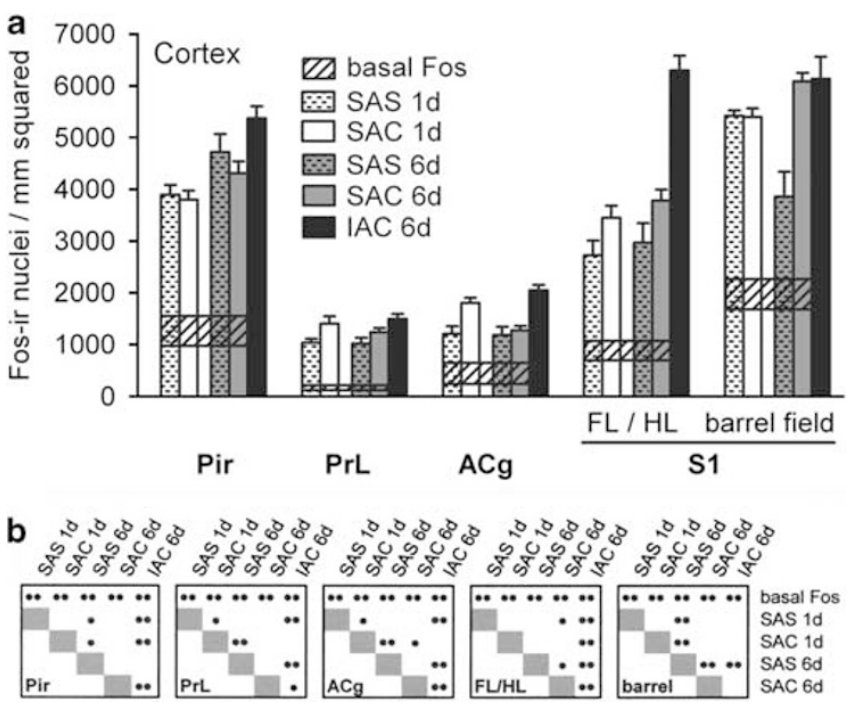

Figure 9 (a-b) Graphs illustrating the density of Fos-immunoreactive nuclei in some cortical structures, including the piriform (Pir), prelimbic $(\mathrm{PrL})$, anterior cingulate $(\mathrm{ACg})$, and primary somatosensory $(\mathrm{SI})$, for the experimental groups as described in the text. Conventions are as in Figure 6. FL/HL, forelimb/hindlimb area; IAC, investigator-administered cocaine; SAC, self-administered cocaine; SAS, self-administered saline.

but the subthalamic nucleus, SAC-elicited Fos expression was further increased after 6 sessions as compared with 1 session. SAS-elicited Fos expression after 6 sessions as compared with 1 session was uniformly unchanged in all of these structures, except the lateral division of the central amygdala and zona incerta, where it was increased. Thus, in this pattern, cocaine robustly enhances Fos expression on days 1 and 6 in a manner that sensitizes with repeated administrations.

Evaluated extended amygdala structures and the ventral division of the lateral septum exhibited SAC-elicited Fos expression that was statistically similar or marginally greater than the relevant SAS control on days 1 or 6 . In nearly all of these structures, however, robustly sensitized Fos responses were observed after repeated saline administrations.

$S A C$ vs IAC. Means for Fos-ir neuron density were significantly greater in the IAC 6 day group than in the SAC 6 day group in the accumbens rostral pole (Figure 6a) and core (Figure 6a), central part of the caudate-putamen (Figure 6b), intermediate division of the lateral septum (Figure 7b), medial division of the lateral habenula (Figure 7b), zona incerta (Figure 7b), VTA (Figure 8a), rostral division of the rostromedial tegmental nucleus (Figure 8a), laterodorsal tegmental nucleus (Figure 8a), piriform cortex (Figure 9), prelimbic cortex (Figure 9), anterior cingulate cortex (Figure 9), and the forelimb/ hindlimb part of the S1 somatosensory area (Figure 9). In contrast, the IAC 6 day value was significantly below that of the SAC 6 day group in the medial division of the central amygdaloid nucleus (Figure 7a) and it trended toward lesser in the dorsolateral division of the bed nucleus of stria terminalis (Figure 7a) and paraventricular nucleus of the hypothalamus (Figure $8 \mathrm{~b}$ ). In the remaining structures the IAC 6 day and SAC 6 day values were not different. 


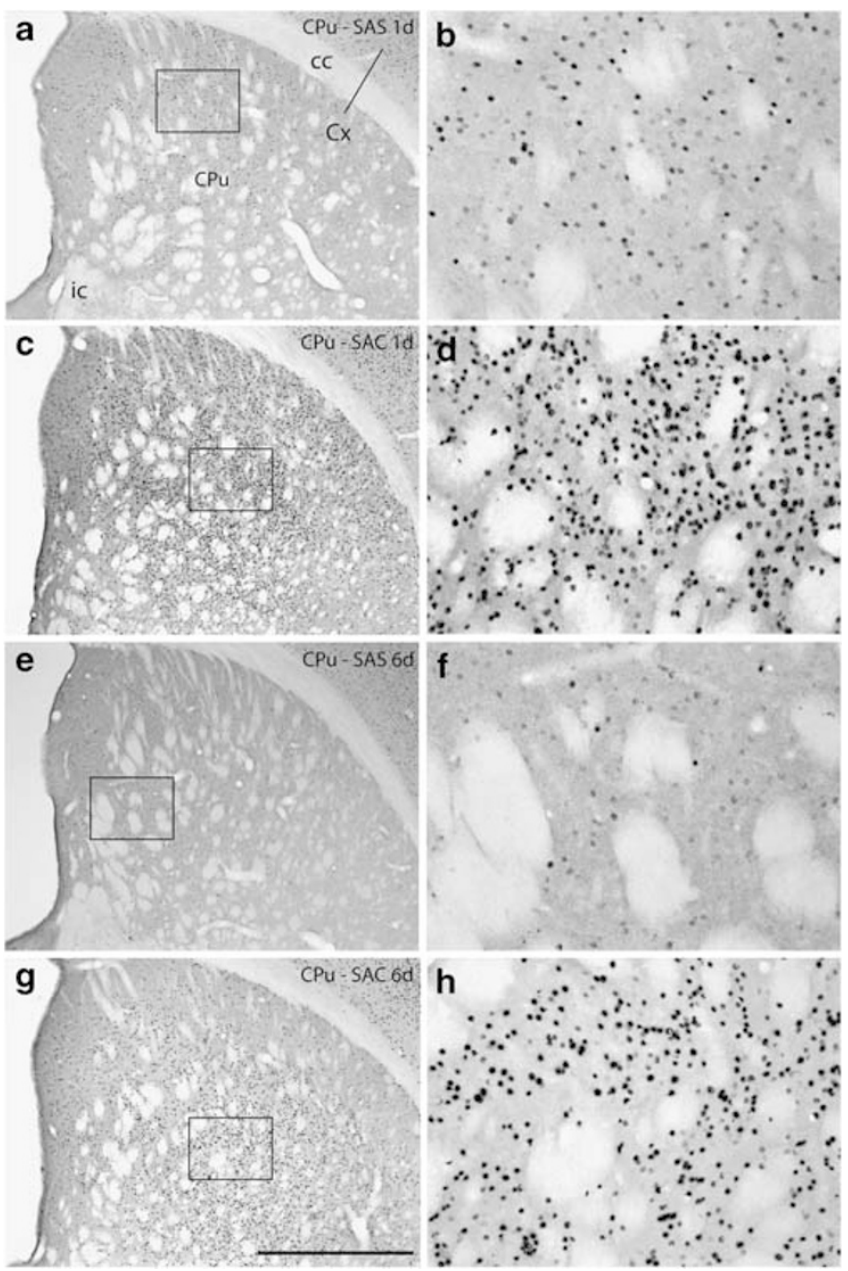

Figure 10 Photomicrographs illustrating Fos immunoreactive neurons in the caudate-putamen $(\mathrm{CPu})$ in the I (Id) and $6(6 \mathrm{~d})$ day saline selfadministration (SAS, panels $a, b, e$, and $f$ ) and cocaine self-administration (SAC, panels $c, d, g$, and $h$ ) groups. $b, d, f$, and $h$ are enlargements of the boxed areas in a, c, e, and g, respectively. cc, corpus callosum; Cx, cortex; ic, internal capsule. Scale bar: I $\mathrm{mm}$ in a, c, e, and g; $200 \mu \mathrm{m}$ in $b, d, f$, and $h$.

\section{DISCUSSION}

Data described herein suggest that the expression and recalibration of Fos reflect roles that various functionalanatomical subdivisions of the forebrain have in mediating behavioral activation associated with early phases of cocaine and saline self-administration.

\section{Methodological Considerations}

Although Fos expression unambiguously marks cells as opposed to axons, it is not necessarily an indication of 'activation', but rather can be triggered by changes in intracellular signaling or neuronal activity, or both, depending on the stimulus and brain structure evaluated (Sharp et al, 1993; Farivar et al, 2004). It is also important to emphasize that a pattern of brain Fos-labeling observed at any given point during a course of cocaine self-administration is not representative of other points (White and Kalivas, 1998; Nestler, 2001a; b). We selected 1 day and 6

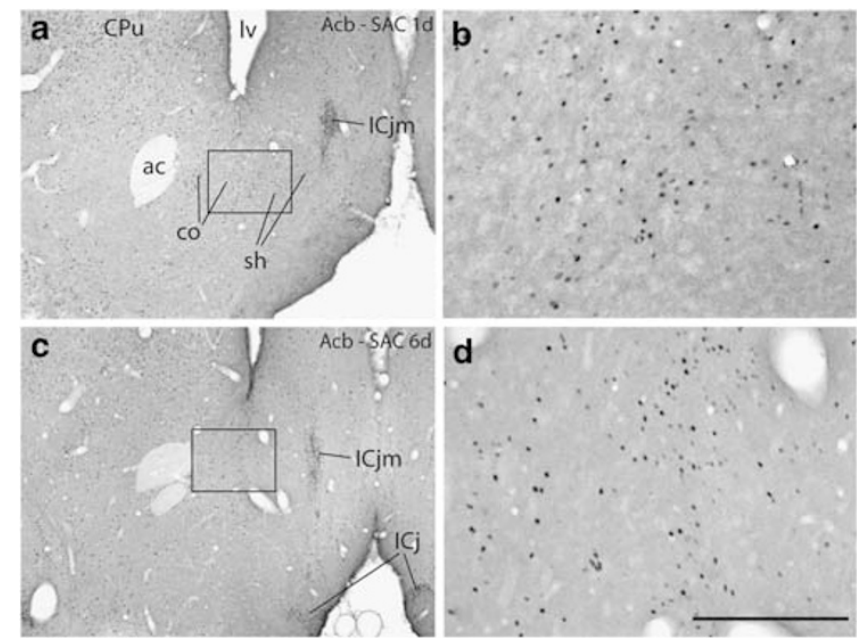

Figure II Photomicrographs illustrating Fos immunoreactive neurons in the accumbens (Acb) in the $I$ (Id) and 6 (6d) day cocaine selfadministration (SAC) groups. $b$ and $d$ are enlargements of the boxed areas in a and c, respectively. ac, anterior commissure; co, Acb core; sh, Acb shell; CPu, caudate-putamen; ICj, island of Calleja; ICjm, island of Calleja magnus; l, lateral ventricle. Scale bar: I mm in a, c, and e; $200 \mu \mathrm{m}$ in b, $\mathrm{d}$, and $\mathrm{f}$.

day groups to represent, respectively, acute responses and the responses when rats have habituated to self-administering, but do not exhibit overt signs of withdrawal between sessions.

SAS rats were slightly less active in the self-administration chambers than SAC rats, particularly on days 3-6 (Figure $3 b$ and c), but the slight differences in locomotion seem unlikely to explain the robustly greater Fos expression observed in the SAC rats. Actually, the expression of Fos in the SAS rats was equivalent to that in SAC brains in about one-third of the evaluated structures. In contrast, rats that were anesthetized in the home cage (basal Fos group) exhibited little Fos expression. Presumably, much Fos expression observed in both SAS and SAC brains was related to arousing stimuli associated with transferring the rats from home cage to the self-administration environment, akin to the enhanced effects on Fos expression that Robinson and colleagues have associated with self-administration in a novel environment (Day et al, 2001).

Similar amounts of cocaine and saline were delivered per session from the first through the sixth day, such that the 6 day and 1 day groups were exposed to the same number of infusions. Although less effort to achieve this result was exerted on successive days (Figure $3 \mathrm{~b}$ and $\mathrm{c}$ ), it is unlikely that the greater activity of SAC 1 day rats explains the differences in Fos expression because so many structures in the less active SAC 6 day rats exhibited significantly greater Fos expression (Table 2). In an earlier relevant study (Neisewander et al, 2000), Fos expression associated with locomotion occurred only in the accumbens core, where no differences distinguished the SAC 1 day and 6 day groups in this study.

Observed differences in the corresponding 1 day and 6 day SAS and SAC groups could stem from systematic differences attached to the presence of tracer injections in 6 day rats or the independent self-administration sessions 
Table 2 Comparisons of Means Graphed in Figures (6-9) Reflecting Fos Densities (Fos-ir nuclei/mm²) for (A) Cocaine (SAC) vs Saline (SAS) Self-Administration On Days I and 6 and (B) After 6 vs I Day of SAC or SAS

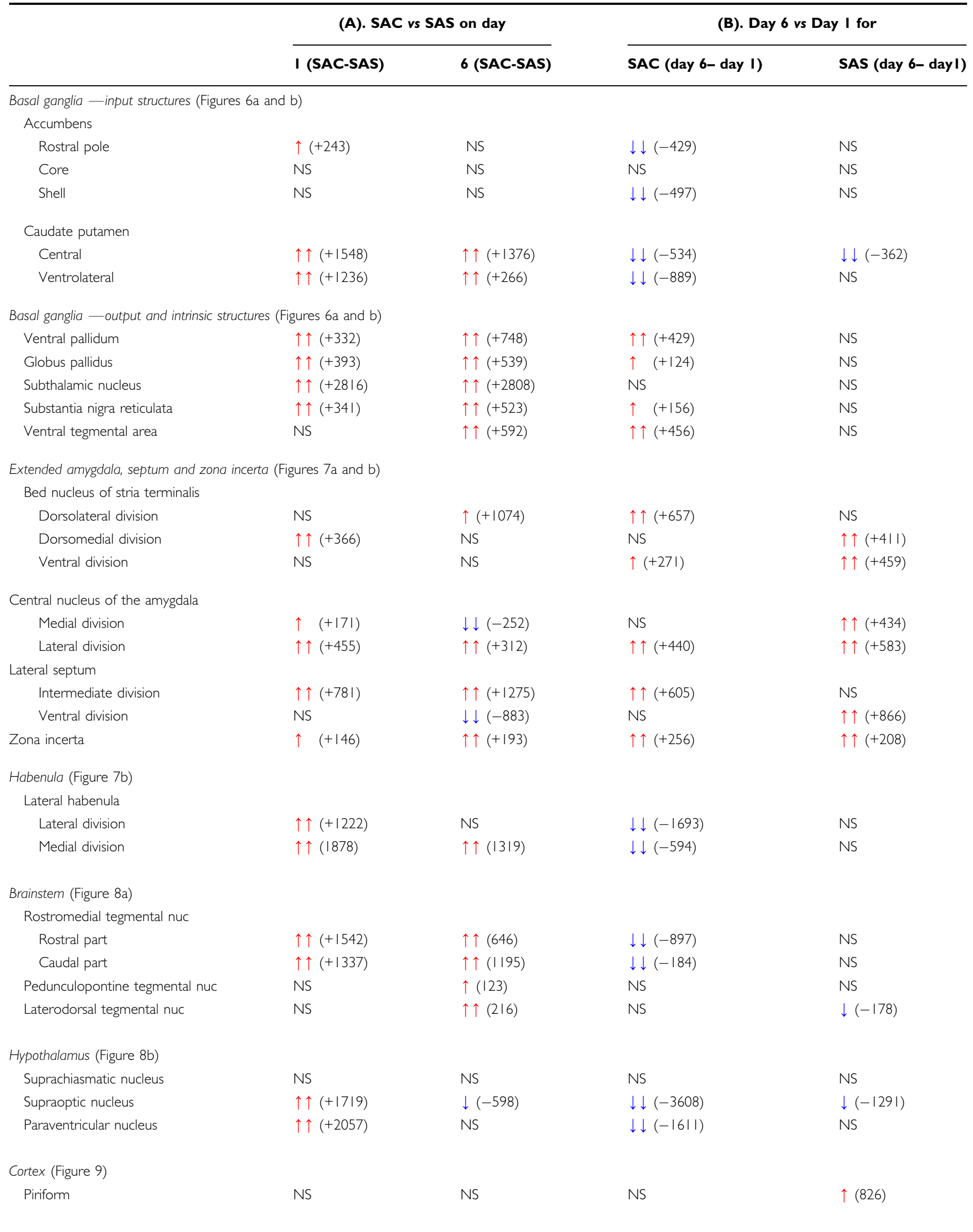


(A). SAC vs SAS on day

(B). Day 6 vs Day I for

\begin{tabular}{|c|c|c|c|c|}
\hline & & \\
\hline & I (SAC-SAS) & 6 (SAC-SAS) & SAC (day 6-day I) & SAS (day 6-day I) \\
\hline Prelimbic & $\uparrow(+366)$ & NS & NS & NS \\
\hline Anterior cingulate & $\uparrow(+597)$ & NS & $\downarrow(-530)$ & NS \\
\hline \multicolumn{5}{|l|}{ Somatosensory } \\
\hline forelimb/hindlimb & NS & NS & NS & NS \\
\hline Barrel & NS & $\uparrow \uparrow(+2226)$ & NS & $\downarrow \downarrow(-1565)$ \\
\hline
\end{tabular}

Symbols indicate that SAC (in A) and day 6 (in B) Fos expressions were greater $(\uparrow[p<0.5]$, $\uparrow \uparrow[p<0.0$ I $]$ ), lesser $(\downarrow[p<0.5], \downarrow \downarrow[p<0.0$ I $]$ ) or not significantly different (NS) from SAS and day I, respectively. Numbers in paretheses indicate the actual magnitudes of significant responses, reflecting (in A) mean SAC values after the respective SAS means had been subtracted out and (in B) mean day 6 values after the respective day I means had been subtracted out. Note in numerous structures, that repeated saline self-administration produces Fos responses that are significantly changed over 6 days (column B, SAS). Particularly in extended amygdala structures, septum and zona incerta, the Fos response to repeated SAS is nearly uniformly increased, such that the apparent enhancement of Fos expression in these structures after day 6 as compared with day I of SAC is accounted for in part by an increase in Fos expression due to repetition of self-administration. For similar reasons, decreased Fos expression observed in the central part of the caudate-putamen after 6 as compared with day I of SAC may be accounted for in part by the decrease in Fos expression associated with repetition of self-administration.

and immunohistochemical batches to which the 1 and 6 day groups were subjected, or a combination of these, rather than actual differences in the respective Fos responses. Arguing against this notion, some SAS 6 day $(n=2)$ and SAC 6 day $(n=2)$ rats batch-processed together with the corresponding 1 day groups produced amounts of Fosexpression comparable with the previously run 6 day brains. Second, had either the 1 day or 6 day batch been subjected to suboptimal self-administration or immunohistochemistry, sections from that batch should have had uniformly less Fos-labeling, but this was not observed.

\section{IAC vs SAC}

Fos-ir neuron densities in the group that received investigator-administered cocaine (IAC 6 day) exceeded those in the SAC 6 day group in several structures, possibly because IAC 6 day rats, while receiving the same amount of cocaine as SAC 6 day rats, got fewer, larger injections. The argument against this idea is that structures showing enhanced Fos expression in IAC 6 day rats as compared with SAC 6 day rats were outnumbered by those with equivalent or lesser Fos densities. Another possibility is that volitional control of repeated drug administration, ie, agency, may act to suppress cocaine-elicited Fos expression in some structures. Consistent with this notion, structures with less Fos expression in the SAC 6 day rats, which learned a task, occupied mainly the cortex and basal ganglia, including the caudate-putamen and accumbens, of which all contribute to planning and initiating learned voluntary actions (Pasupathy and Miller, 2005) and become less active as task acquisition proceeds (Kleim et al, 1996; Nordquist et al, 2003).

\section{Basal Ganglia Input, Output, and Intrinsic Structures}

Robust increases in Fos expression in the striatum and structures to which it projects were among the most striking effects of acute cocaine self-administration observed in this study. Although Fos expression was further potentiated after 6 consecutive days of cocaine self-administration in structures to which striatum projects, including the globus pallidus, ventral pallidum, substantia nigra reticulata, and VTA (Heimer et al, 1995; Lu et al, 1998; Zahm, 2006), it was desensitized at 6 days in the caudate-putamen and accumbens. These observations can be explained on the basis of connectivity, transmitter phenotypes, and empirical observations. To wit, neurons that give rise to striatal outputs are GABAergic (Ribak et al, 1979; Heimer et al, 1995) and mainly inhibited in vivo by cocaine through dopamine D-1 and D-2 receptors in anesthetized preparations (Henry et al, 1989, Henry and White, 1991; White et al., 1993) and unanesthetized preparations during cocaine self-administration sessions (Carelli and Deadwyler, 1994; 1997; Peoples et al, 1998). Inhibition of striatal neurons by dopamine following acute SAC should disinhibit, ie, 'activate', the output and intrinsic structures to which GABAergic striatal neurons project, consistent with expression of Fos in those structures. Repeated administrations of cocaine further enhance striatal dopamine release (Kalivas and Duffy, 1990), produce dopamine D-1 receptor supersensitivity (Henry et al, 1989; Henry and White, 1991; 1995) and transiently upregulate accumbens dopamine D-2 receptor density (Kleven et al, 1990; Peris et al, 1990), which together further inhibit striatal neurons (Henry and White, 1995) and presumably potentiate Fos expression in striatal output and intrinsic structures, as observed on day 6 in this study. Because behavioral activation has long been recognized to be inversely correlated with the activity of striatal neurons, but directly correlated with that of striatal output structures, such as the ventral pallidum/substantia innominata (Mogenson and Yang, 1991; Mogenson et al, 1993), we can postulate that the pattern of cocaine-elicited basal ganglia Fos expression observed in this study identifies pathways by which behaviorally activating effects of cocaine, which are exerted directly mainly on striatal neurons, are disseminated widely through the brain through basal ganglia output structures and, in turn, the reticular formation, to which basal ganglia output structures project (Zahm, 2006). Consistent with this idea, Fos expression was potentiated in the zona incerta and pedunculopontine and laterodorsal tegmental nuclei at 6 days in this study. 
Although nearly all striatal medium spiny neurons are electrophysiologically inhibited following the administration of cocaine (White et al, 1993), expression of Fos in response to acute administration of cocaine occurs in only about half, ie, those in which D-1 is the dominant dopamine receptor subtype (Young et al, 1991). Conditional knockout of Fos expression in these neurons disrupts the expression of several proteins normally induced by cocaine and prevents the development of cocaine-elicited behavioral sensitization (Zhang et al, 2006). In addition, a gradual accumulation of other Fos family transcription factors, including FosB and $\Delta$ FosB, a long-lived splice variant of FosB (Chen et al, 1995), occurs in striatal D-1 expressing neurons during repeated cocaine administration (Kelz et al, 1999). A build-up of $\Delta$ FosB in the accumbens, which is attenuated in the conditional knockout of Fos expression described above (Zhang et al, 2006), correlates with the development of augmented locomotor responses to cocaine, enhanced sensitivity to the rewarding properties of cocaine, and enhanced self-administration of lower doses of cocaine (Nestler, 2008). $\Delta$ FosB also disrupts normal transcriptional regulation of proteins induced by cocaine (Kelz et al, 1999), including Fos (Renthal et al, 2008) and some reported to be perturbed by Fos (Zhang et al, 2006). Expression of the $\alpha$-amino-3-hydroxy-5-methyl-4-isoxazolepropionic acid (AMPA) receptor subunit 2 (GluR2) is regulated by Fos (Zhang et al, 2006) and increased by $\Delta$ FosB (Nestler, 2008) with a resulting decrease in AMPA channel conductance and accompanying sensitivity to glutamate. This, together with the development of decreased sodium and calcium voltageactivated currents (Zhang et al, 1998; 2002), contributes to the decreased activity and increased inhibition of medium spiny neurons by dopamine that accompany repeated cocaine. Furthermore, it indicates that Fos and $\Delta$ FosB expression not only signal, but also are necessary for the enhanced inhibition. Inhibition of Fos expression by $\Delta$ FosB is the likely basis for the desensitized striatal Fos response observed at 6 day as compared with 1 day of cocaine selfadministration in this study (see also Moratalla et al, 1996).

\section{Extended Amygdala and Ventral Lateral Septum}

A majority of extended amygdala structures evaluated in this study exhibited Fos expression equivalent to or greater than the controls following acute SAC. We included the ventral division of the lateral septum with these structures because it lies adjacent to the extended amygdala (ie, the bed nucleus of stria terminalis) and shares with it similar connections and, presumably, functions (Risold and Swanson, 1997). After 6 days of cocaine self-administration, responses in these structures were mixed, with some showing greater, others equivalent, and others less Fos expression than their counterparts in SAS brains. Interestingly, most extended amygdala subdivisions of rats that self-administered saline exhibited robustly increased Fos expression on day 6 as compared with day 1, such that the tendency for SAC as compared with SAS Fos expression in extended amygdala to be greater on day 1 was reversed on day 6. For example, the ventral division of the lateral septum and medial division of the central amygdaloid nucleus went from exhibiting significantly greater Fos expression in the SAC as compared with SAS groups on day 1 to exhibiting significantly less on day 6 . In view of this effect of repeated saline self-administration, increased Fos expression observed in SAC rats in most extended amygdala structures on day 6 as compared with day 1 might be due as much to the act of self-administering (as in saline selfadministration) as to the effects of cocaine. Insofar as extended amygdala and lateral septum are implicated not only in neural responses to fear and anxiety (LeDoux et al, 1988; LeDoux, 1992; Duncan et al, 1996; Petrovich and Swanson 1997; Davis and Shi, 1999; Sheehan et al, 2004; Phelps and LeDoux, 2005; Zahm and Trimble, 2008), but also arousal (Asmus and Newman 1994; Sheehan et al, 2004; Deurveilher et al, 2006; Valdés et al, 2006; Schiltz et al. 2007), increased Fos expression in the extended amygdala on day 6 may reflect arousal or anxiety that accompanies repeated self-administration.

\section{Concluding Comments}

Although current thought emphasizes a putative shift of processing from ventral to dorsal striatum as drug-seeking become habitual (Everitt and Robbins 2005; Belin and Everitt, 2008), the present data reveal that both dorsal and ventral striatopallidum are robustly engaged by cocaine from the very earliest stages of a course of self-administration, which is consistent with previous studies (Graybiel et al, 1990; Young et al, 1991), and recalibrate Fos expression similarly, at least during the first 6 days. Fos expression accompanies cocaine-elicited inhibition of striatum, but, because Fos often signals 'activation,' it is reasonable to speculate that the potentiation of Fos expression in basal ganglia output structures reflects activation and accompanying dissemination of behaviorally activating effects of cocaine widely through the brain. Fos expression in the extended amygdala, zona incerta, and ventral division of the lateral septum, while either unaffected or mildly increased following acute SAC, was robustly increased following repeated SAC, although whether due to cocaine or arousing aspects of repeated responding is uncertain. Nonetheless, if in these instances Fos does reflect neuronal activation, it would appear that striatopallidum, extended amygdala, and related structures contribute together to the crescendo of behavioral activation and accompanying reinforcement that occurs early during a course of cocaine self-administration, impelling the descent toward addiction.

Fos expression in inhibited medium spiny neurons seeds the expression of longer-lived Fos family transcription factors (Chen et al, 1995; Kelz et al, 1999; Zhang et al, 2006) that, in turn, modulate the transcription of numerous proteins, including Fos, in such a way as to disrupt neuronal homeostasis and facilitate addictive behaviors (Nestler, 2008). Several other structures evaluated in this study, including the lateral and medial habenula, rostromedial tegmental nucleus, supraoptic and paraventricular nuclei, and anterior cingulate cortex, exhibited an absolute decline in cocaine-elicited Fos expression upon repeated exposures. In addition, as described above, a decline in repeated cocaine-elicited Fos expression relative to repeated salineelicited Fos expression occurs in the central nucleus of the amygdala and ventral division of the lateral septum, suggesting that a reduction of Fos expression in response 
to repeated cocaine also involves the extended amygdala. Whether a $\Delta$ FosB-related neuroadaptation accounts for the attenuation of cocaine-elicited Fos expression over repeated administrations in all of these structures is unknown, but early results suggest that this is so in the prelimbic cortex (Winstanley et al, 2009) and rostromedial tegmental nucleus (Kaufling et al, 2009). To the extent that such neuroadaptations may ultimately contribute to profound dysregulations of neuronal function, the present data indicate that cocaineelicited pathology may be more widespread than previously thought.

\section{DISCLOSURE}

The authors declare that, except for income received from their primary employer, no financial support or compensation has been received from any individual or corporate entity over the past 3 years for research or professional service and there are no personal financial holdings that could be perceived as constituting a potential conflict of interest.

\section{ACKNOWLEDGEMENTS}

We gratefully acknowledge the expert technical assistance of Anita Cheng, Jennifer Jackolin, and Lindsay Cotterly. This work was supported by USPHS Grants NIH NS-23805 and DA-15207 (DSZ), DA-20654 (MM) and DA-16662 (GEM).

\section{REFERENCES}

Alheid GF, Heimer L (1988). New perspectives in basal forebrain organization of special relevance for neuropsychiatric disorders: the striatopallidal, amygdaloid and corticopetal components of substantia innominata. Neuroscience 27: 1-39.

Asmus SE, Newman SW (1994). Colocalization of tyrosine hydroxylase and Fos in the male Syrian hamster brain following different states of arousal. J Neurobiol 25: 156-168.

Balster RL (1990). Abuse potential of buspirone and related drugs. J Clin Psychopharmacol 10: 31S-37S.

Bauer LO, Kranzler HR (1994). Electroencephalographic activity and mood in cocaine-dependent outpatients: effects of cocaine cue exposure. Biol Psychiat 36: 189-197.

Bekavac I, Waterhouse BD (1995). Systemically administered cocaine selectively enhances long-latency responses of rat barrel field cortical neurons to vibrissae stimulation. J Pharmacol Exp Ther 272: 333-342.

Belin D, Everitt BJ (2008). Cocaine seeking habits depend upon dopamine-dependent serial connectivity linking the ventral with the dorsal striatum. Neuron 57: 432-441.

Bossert JM, Ghitza UE, Lu L, Epstein DH, Shaham Y (2005). Neurobiology of relapse to heroin and cocaine seeking: an update and clinical implications. Eur J Pharmacol 526: 36-50.

Breiter HC, Gollub RL, Weisskoff RM, Kennedy DN, Makris N, Berke JD et al. (1997). Acute effects of cocaine on human brain activity and emotion. Neuron 19: 591-611.

Carelli RM, Deadwyler SA (1994). A comparison of nucleus accumbens neuronal firing patterns during cocaine selfadministration and water reinforcement in rats. J Neurosci 14: 7735-7746.

Carelli RM, Deadwyler SA (1997). Cellular mechanisms underlying reinforcement-related processing in the nucleus accumbens: electrophysiological studies in behaving animals. Pharmacol Biochem Behav 57: 495-504.
Cenci MA, Campbell K, Wictorin K, Björklund A (1992). Striatal cfos induction by cocaine or apomorphine occurs preferentially in output neurons projecting to the substantia nigra in the rat. Eur J Neurosci 4: 376-380.

Chen J, Nye HE, Kelz MB, Hiroi N, Nakabeppu Y, Hope BT et al. (1995). Regulation of delta FosB and FosB-like proteins by electroconvulsive seizure and cocaine treatments. Mol Pharmacol 48: 880-889.

Childress AR, Ehrman RN, McLellan AT, O’Brien CP (1988). Conditioned craving and arousal in cocaine addiction: A preliminary report. In: Harris LS (ed). Problems of Drug Dependence, 1987 National Institute on Drug Abuse Research Monograph 81. DHHS Pub. No. (ADM)88-1564 Supt Of Docs, US Government Print Off: Washington, DC, pp: 74-80.

Coggeshall RE, Lekan HA (1996). Methods for determining numbers of cells and synapses: a case for more uniform standards of review. J Comp Neurol 364: 6-15.

Conrad KL, Tseng KY, Uejima JL, Reimers JM, Heng LJ, Shaham Y et al. (2008). Formation of accumbens GluR2-lacking AMPA receptors mediates incubation of cocaine craving. Nature 454: 118-121.

Crombag HS, Jedynak JP, Redmond K, Robinson TE, Hope BT (2002). Locomotor sensitization to cocaine is associated with increased Fos expression in the accumbens, but not in the caudate. Behav Brain Res 136: 455-462.

Curran T, Morgan JI (1985). Superinduction of c-fos by nerve growth factor in the presence of peripherally active benzodiazepines. Science 229: 1265-1268.

Davis M, Shi C (1999). The extended amygdala: are the central nucleus of the amygdala and the bed nucleus of the stria terminalis differentially involved in fear and anxiety? Ann NY Acad Sci 877: 292-308.

Day HE, Badiani A, Uslaner JM, Oates MM, Vittoz NM, Robinson TE et al. (2001). Environmental novelty differentially affects c-fos mRNA expression induced by amphetamine or cocaine in subregions of the bed nucleus of the stria terminalis and amygdala. J Neurosci 21: 732-740.

Deurveilher S, Lo H, Murphy JA, Burns J, Semba K (2006). Differential c-Fos immunoreactivity in arousal-promoting cell groups following systemic administration of caffeine in rats. J Comp Neurol 498: 667-689.

de Wit H, Stewart J (1981). Reinstatement of cocaine-reinforced responding in the rat. Psychopharmacol 75: 134-143.

Duncan GE, Knapp DJ, Breese GR (1996). Neuroanatomical characterization of Fos induction in rat behavioral models of anxiety. Brain Res 713: 79-91.

Drouin C, Waterhouse BD (2004). Cocaine-induced vs behaviourrelated alterations of spontaneous and evoked discharge of somatosensory cortical neurons. Eur J Neurosci 19: 1016-1026.

Einhorn LC, Johansen PA, White FJ (1988). Electrophysiological effects of cocaine in the mesoaccumbens dopamine system: studies in the ventral tegmental area. J Neurosci 8: 100-112.

Ehrman PN, Robbins SJ, Childress AR, O’Brien CP (1992). Conditioned responses to cocaine-related stimuli in cocaine abuse patients. Psychopharmacol 107: 523-529.

Everitt BJ, Robbins TW (2005). Neural systems of reinforcement for drug addiction: from actions to habits to compulsion. Nat Neurosci 8: 1481-1489.

Fallon JH, Koziell DA, Moore RY (1978). Catecholamine innervation of the basal forebrain. II. Amygdala, suprarhinal cortex and entorhinal cortex. J Comp Neurol 180: 509-532.

Fallon JH, Moore RY (1978a). Catecholamine innervation of the basal forebrain. III. Olfactory bulb, anterior olfactory nuclei, olfactory tubercle and piriform cortex. J Comp Neurol 180: 533-544.

Fallon JH, Moore RY (1978b). Catecholamine innervation of the basal forebrain. IV. Topography of the dopamine projection to 
the basal forebrain and neostriatum. J Comp Neurol 180: $545-580$

Farivar R, Zahngenehpour S, Chaudhuri A (2004). Cellularresolution activity mapping of the brain using immediate-early gene expression. Front Biosci 9: 104-109.

Geisler S, Marinelli M, DeGarmo B, Becker ML, Freiman AJ, Beales $\mathrm{M}$ et al. (2008). Prominent activation of brainstem and pallidal afferents of the ventral tegmental area by cocaine. Neuropsychopharmacol 33: 2688-2700.

Graham JH, Porrino LJ (1995). Neuroanatomical basis of cocaine self-administration. In Hammer RP Jr (edn). The Neurobiology of Cocaine Cellular and Molecular Mechanisms. CRC Press: New York. pp 3-14.

Graybiel AM, Moratalla R, Robertson HA (1990). Amphetamine and cocaine induce drug-specific activation of the $c$-fos gene in striosome-matrix compartments and limbic subdivisions of the striatum. Proc Natl Acad Sci USA 87: 6912-6916.

Heimer L (2003). A new anatomical framework for neuropsychiatric disorders and drug abuse. Am J Psychiat 160: 1726-1739.

Heimer L, Alheid GF, Zahm DS (1995). Basal Ganglia. In Paxinos G (edn). The Rat Nervous System, Volume 1 Forebrain and Midbrain 2nd Edition. Academic Press: Sydney. pp 579-628.

Heimer L, Van Hoesen GW, Trimble M, Zahm DS (2008). Anatomy of Neuropsychiatry. The New Anatomy of the Basal Forebrain and its Implications for Neuropsychiatric Disease. Elsevier: Amsterdam - New York - San Diego.

Heimer L, Van Hoesen GW (2006). The limbic lobe and its output channels: implications for emotional functions and adaptive behavior. Neurosci Biobehav Rev 30: 126-147.

Henry DJ, Greene MA, White FJ (1989). Electrophysiological effects of cocaine in the mesoaccumbens dopamine system: repeated administration. J Pharmacol Exp Ther 251: 833-839.

Henry DJ, White FJ (1991). Repeated cocaine administration causes persistent enhancement of D1 dopamine receptor sensitivity within the rat nucleus accumbens. J Pharmacol Exp Ther 258: 882-890.

Henry DJ, White FJ (1995). The persistence of behavioral sensitization to cocaine parallels enhanced inhibition of nucleus accumbens neurons. J Neurosci 15: 6287-6299.

Hope B, Kosovsky B, Hymen SE, Nestler EJ (1992). Regulation of immediate early gene expression and AP-1 binding in the rat nucleus accumbens by chronic cocaine. Proc Natl Acad Sci USA 89: $5674-5768$.

Howell LL, Byrd LD (1995). Serotonergic modulation of the behavioral effects of cocaine in the squirrel monkey. J Pharmacol Exp Ther 275: 1551-1559.

Howell LL, Hoffman JM, Votaw JR, Landrum AM, Wilcox KM, Lindsey KP (2002). Cocaine-induced brain activation determined by positron emission tomography neuroimaging in conscious rhesus monkeys. Psychopharmacol 159: $154-160$.

Jhou TC, Geisler S, Marinelli M, DeGarmo BA, Zahm DS (2009). The mesopontine rostromedial tegmental nucleus: a structure targeted by the lateral habenula that projects to the ventral tegmental area of Tsai and substantia nigra compacta. J Comp Neurol 513: 566-596.

Jiménez-Rivera CA, Waterhouse BD (1991). Effects of systemically and locally applied cocaine on cerebrocortical neuron responsiveness to afferent synaptic inputs and glutamate. Brain Res 546: 287-296.

Jiménez-Rivera CA, Segarra O, Jiménez Z, Waterhouse BD (2000). Effects of intravenous cocaine administration on cerebellar Purkinje cell activity. Eur J Pharmacol 407: 91-100.

Kalivas PW, Duffy P (1990). Effect of acute and daily cocaine treatment on extracellular dopamine in the nucleus accumbens. Synapse 5: 48-58.
Kaufling J, Veinante P, Pawlowski SA, Freund-Mercier MJ, Barrot $M$ (2009). Afferents to the GABAergic tail of the ventral tegmental area in the rat. J Comp Neurol 513: 597-621.

Kelz MB, Chen J, Carlezon Jr WA, Whisler K, Gilden L, Beckmann $\mathrm{AM}$ et al. (1999). Expression of the transcription factor deltaFosB in the brain controls sensitivity to cocaine. Nature 401: 272-276.

Kleim JA, Lussnig E, Schwarz ER, Comery TA, Greenough WT (1996). Synaptogenesis and Fos expression in the motor cortex of the adult rat after motor skill learning. J Neurosci 16: 45294535.

Kleven MS, Perry BD, Woolverton WL, Seiden LS (1990). Effects of repeated injections of cocaine on D1 and D2 dopamine receptors in rat brain. Brain Res 532: 265-270.

Koe BK (1976). Molecular geometry of inhibitors of the uptake of catecholamines and serotonin synaptosomal preparations of rat brain. J Pharmacol Exp Ther 199: 649-661.

LaRowe SD, Myrick H, Hedden S, Mardikian P, Saladin M, McRae A et al. (2007). Is cocaine desire reduced by $\mathrm{N}$-acetylcysteine? Am J Psychiat 164: 1115-1117.

LeDoux JE, Iwata J, Cicchetti P, Reis DJ (1988). Different projections of the central amygdaloid nucleus mediate autonomic and behavioral correlates of conditioned fear. J Neurosci 8: 2517-2529.

LeDoux JE (1992). Brain mechanisms of emotion and emotional learning. Curr Opin Neurobiol 2: 191-197.

London ED, Cascella NG, Wong DF, Phillips RL, Dannals RF, Links JM et al. (1990). Cocaine-induced reduction of glucose utilization in human brain. A study using positron emission tomography and [fluorine 18]-fluorodeoxyglucose. Arch Gen Psychiat 47: 567-574.

London ED, Wilkerson G, Goldberg SR, Risner ME (1986). Effects of 1-cocaine on cerebral glucose utilization in the rat. Neurosci Letts 68: 73-78.

Lu XY, Ghasemzadeh MB, Kalivas PW (1998). Expression of D1 receptor, D2 receptor, substance $\mathrm{P}$ and enkephalin messenger RNAs in the neurons projecting from the nucleus accumbens. Neuroscience 82: 767-780.

Lyons D, Friedman DP, Nader MA, Porrino LJ (1996). Cocaine alters cerebral metabolism within the ventral striatum and limbic cortex of monkeys. J Neurosci 16: 1230-1238.

Macey DJ, Rice WN, Freedland CS, Whitlow CT, Porrino LJ (2004). Patterns of functional activity associated with cocaine selfadministration in the rat change over time. Psychopharmacol 172: 384-392.

Marinelli M, Cooper DC, Baker LK, White FJ (2003). Impulse activity of midbrain dopamine neurons modulates drug-seeking behavior. Psychopharmacol 168: 84-98.

Mogenson GJ, Brudzynski SM, Wu M, Yang CR, Yim CCY (1993). From motivation to action: a review of dopaminergic regulation of limbic-nucleus accumbens-ventral pallidum-pedunculopontine tegmental nucleus circuitries involved in limbic-motor integration. In Kalivas PW, Barnes CD (eds) Limbic Motor Circuits and Neuropsychiatry. CRC Press: Boca Raton, pp: 193-236.

Mogenson GJ, Yang CR (1991). The contribution of basal forebrain to limbic-motor integration and the mediation of motivation to action. In Napier CT, Kalivas PW, Hanin I (eds) The Basal Forebrain Anatomy to Function, Advances in Experimental Medicine and Biology, Volume 295. Plenum Press: New York. pp 267-290.

Morgan JI, Curran T (1991). Stimulus-transcription coupling in the nervous systems: involvement of the inducible proto-oncogenes fos and jun. Annu Rev Neurosci 14: 421-451.

Moratalla R, Elibol B, Vallejo M, Graybiel AM (1996). Networklevel changes in expression of inducible Fos-Jun proteins in the striatum during chronic cocaine treatment and withdrawal. Neuron 17: 147-156. 
Moratalla R, Vickers EA, Robertson HA, Cochran BH, Graybiel AM (1993). Coordinate expression of c-fos and jun B is induced in the rat striatum by cocaine. J Neurosci 13: 423-433.

Moussawi K, Pacchioni A, Moran M, Olive MF, Gass JT, Lavin A et al. (2009). N-acetylcysteine reverses cocaine-induced metaplasticity. Nat Neurosci 12: 182-189.

Mullen RJ, Buck CR, Smith AM (1992). NeuN, a neuronal specific nuclear protein in vertebrates. Development 116: 201-211.

Neisewander JL, Baker DA, Fuchs RA, Tran-Nguyen LT, Palmer A, Marshall JF (2000). Fos protein expression and cocaine-seeking behavior in rats after exposure to a cocaine self-administration environment. J Neurosci 20: 798-805.

Nestler EJ (2001a). Molecular neurobiology of addiction. Am J Addict 10: 201-217.

Nestler EJ (2001b). Molecular basis of long-term plasticity underlying addiction. Nat Rev Neurosci 2: 119-128.

Nestler EJ (2005). The neurobiology of cocaine addiction. Sci Pract Perspect 3: 4-10.

Nestler EJ (2008). Transcriptional mechanisms of addiction: role of DeltaFosB. Philos Trans $R$ Soc Lond B Biol Sci 363: 3245-3255.

Nordquist RE, Pennartz CM, Uylings HB, Joosten RN, Jonker AJ, Groenewegen HJ et al. (2003). C-fos activation patterns in rat prefrontal cortex during acquisition of a cued classical conditioning task. Behav Brain Res 146: 65-75.

O’Brien CP (2005). Anticraving medications for relapse prevention: a possible new class of psychoactive medications. Am J Psychiat 162: 8.

O'Brien CM, Childress AR, McLellan AT, Ehrman R (1990). Integrating systemic cue exposure with standard treatment in recovering drug dependent patients. Addict Behav 15: 355-365.

Pasupathy A, Miller EK (2005). Different time courses of learningrelated activity in the prefrontal cortex and striatum. Nature 433: 873-876.

Peoples LL, Uzwiak AJ, Guyette FX, West MO (1998). Tonic inhibition of single nucleus accumbens neurons in the rat: a predominant but not exclusive firing pattern induced by cocaine self-administration sessions. Neuroscience 86: 13-22.

Peris J, Boyson SJ, Cass WA, Curella P, Dwoskin LP, Larson G et al. (1990). Persistence of neurochemical changes in dopamine systems after repeated cocaine administration. J Pharmacol Exp Ther 253: 38-44.

Petrovich GD, Swanson LW (1997). Projections from the lateral part of the central amygdalar nucleus to the postulated fear conditioning circuit. Brain Res 763: 247-254.

Phelps EA, LeDoux JE (2005). Contributions of the amygdala to emotion processing: from animal models to human behavior. Neuron 48: 175-187.

Porrino LJ (1993). Functional consequences of acute cocaine treatment depend on route of administration. Psychopharmacol 112: 343-351.

Porrino LJ, Domer FR, Crane AM, Sokoloff L (1988). Selective alterations in cerebral metabolism within the mesocorticolimbic dopaminergic system produced by acute cocaine administration in rats. Neuropsychopharmacol 1: 109-118.

Porrino LJ, Lyons D, Miller MD, Smith HR, Friedman DP, Daunais JB et al. (2002). Metabolic mapping of the effects of cocaine during the initial phases of self-administration in the nonhuman primate. J Neurosci 22: 7687-7694.

Renthal W, Carle TL, Maze I, Covington 3rd HE, Truong HT, Alibhai I et al. (2008). Delta FosB mediates epigenetic desensitization of the c-fos gene after chronic amphetamine exposure. J Neurosci 28: 7344-7349.

Ribak CE, Vaughn JE, Roberts E (1979). The GABA neurons and their axon terminals in rat corpus striatum as demonstrated by GAD immunocytochemistry. J Comp Neurol 187: 261-283.

Risold PY, Swanson LW (1997). Chemoarchitecture of the rat lateral septal nucleus. Brain Res Rev 24: 91-113.
Ritz MC, Lamb RJ, Goldberg SR, Kuhar MJ (1987). Cocaine receptors on dopamine transporters are related to self-administration of cocaine. Science 237: 1219-1223.

Roberts DC, Phelan R, Hodges LM, Hodges MM, Bennett B, Childers $S$ et al. (1999). Self-administration of cocaine analogs by rats. Psychopharmacol 144: 389-397.

Rutter JJ, Baumann MH, Waterhouse BD (1998). Systemically administered cocaine alters stimulus-evoked responses of thalamic somatosensory neurons to perithreshold vibrissae stimulation. Brain Res 798: 7-17.

Samaha AN, Mallet N, Ferguson SM, Gonon F, Robinson TE (2004). The rate of cocaine administration alters gene regulation and behavioral plasticity: implications for addiction. $J$ Neurosci 24: $6362-6370$

Saper CB (1996). Any way you cut it: a new journal policy for the use of unbiased counting methods. J Comp Neurol 364: 5.

Schiltz CA, Bremer QZ, Landry CF, Kelley AE (2007). Foodassociated cues alter forebrain functional connectivity as assessed with immediate early gene and proenkephalin expression. BMC Biol 5: 16.

Shaham Y, Hope BT (2005). The role of neuroadaptations in relapse to drug seeking. Nat Neurosci 8: 1437-1439.

Sharkey J, McBean DE, Kelly PA (1991). Acute cocaine administration effects on local cerebral blood flow and metabolic demand in the rat. Brain Res 548: 310-314.

Sharp FR, Sagar SM, Swanson RA (1993). Metabolic mapping with cellular resolution: c-fos vs 2-deoxyglucose. Crit Rev Neurobiol 7: 205-228.

Sheehan TP, Chambers RA, Russell DS (2004). Regulation of affect by the lateral septum: implications for neuropsychiatry. Brain Res Rev 46: 71-117.

Swanson LW (2000). Cerebral hemisphere regulation of motivated behavior. Brain Res 886: 113-164.

Thomas MJ, Kalivas PW, Shaham Y (2008). Neuroplasticity in the mesolimbic dopamine system and cocaine addiction. $\mathrm{Br} J$ Pharmacol 154: 327-342.

Uslaner JM, Crombag HS, Ferguson SM, Robinson TE (2003). Cocaine-induced psychomotor activity is associated with its ability to induce c-fos mRNA expression in the subthalamic nucleus: effects of dose and repeated treatment. Eur J Neurosci 17: $2180-2186$.

Uslaner J, Badiani A, Day HE, Watson SJ, Akil H, Robinson TE (2001a). Environmental context modulates the ability of cocaine and amphetamine to induce c-fos mRNA expression in the neocortex, caudate nucleus, and nucleus accumbens. Brain Res 920: 106-116.

Uslaner J, Badiani A, Norton CS, Day HE, Watson SJ, Akil H et al. (2001b). Amphetamine and cocaine induce different patterns of c-fos mRNA expression in the striatum and subthalamic nucleus depending on environmental context. Eur J Neurosci 13: 1977-1983.

Valdés JL, Maldonado P, Recabarren M, Fuentes R, Torrealba F (2006). The infralimbic cortical area commands the behavioral and vegetative arousal during appetitive behavior in the rat. Eur J Neurosci 23: 1352-1364.

Vanover KE, Nader MA, Woolverton WL (1992). Evaluation of the discriminative stimulus and reinforcing effects of sertraline in rhesus monkeys. Pharmacol Biochem Behav 41: 789-793.

Wee S, Woolverton WL (2004). Evaluation of the reinforcing effects of atomoxetine in monkeys: comparison to methylphenidate and desipramine. Drug Alcohol Depend 75: 271-276.

White FJ, Hu XT, Henry DJ (1993). Electrophysiological effects of cocaine in the rat nucleus accumbens: microiontophoretic studies. J Pharmacol Exp Ther 266: 1075-1084.

White FJ, Kalivas PW (1998). Neuroadaptations involved in amphetamine and cocaine addiction. Drug Alcohol Depend 51: 141-153. 
Willuhn I, Steiner H (2006). Motor-skill learning-associated gene regulation in the striatum: effects of cocaine. Neuropsychopharmacol 31: 2669-2682.

Willuhn I, Sun W, Steiner H (2003). Topography of cocaineinduced gene regulation in the rat striatum: relationship to cortical inputs and role of behavioural context. Eur J Neurosci 17: 1053-1066.

Winstanley CA, Green TA, Theobald DE, Renthal W, Laplant Q, Dileone RJ et al. (2009). DeltaFosB induction in orbitofrontal cortex potentiates locomotor sensitization despite attenuating the cognitive dysfunction caused by cocaine. Pharmacol Biochem Behav 93: 278-284.

Woolverton WL (1987). Evaluation of the role of norepinephrine in the reinforcing effects of psychomotor stimulants in rhesus monkeys. Pharmacol Biochem Behav 26: 835-839.

Young ST, Porrino LJ, Iadarola MJ (1991). Cocaine induces striatal c-fos-immunoreactive proteins via dopaminergic D1 receptors. Proc Natl Acad Sci USA 88: 1291-1295.
Zahm DS (2006). The evolving theory of basal forebrain functional-anatomical 'macrosystems'. Neurosci Biobehav Rev 30: $148-172$.

Zahm DS, Trimble M (2008). The dopaminergic projection system, basal forebrain macrosystems, and conditioned stimuli. CNS Spectr 13: 32-40.

Zavala AR, Biswas S, Harlan RE, Neisewander JL (2007). Fos and glutamate AMPA receptor subunit coexpression associated with cue-elicited cocaine-seeking behavior in abstinent rats. Neuroscience 145: 438-452.

Zhang J, Zhang L, Jiao H, Zhang Q, Zhang D, Lou D et al. (2006). cFos facilitates the acquisition and extinction of cocaine-induced persistent changes. J Neurosci 26: 13287-13296.

Zhang XF, Cooper DC, White FJ (2002). Repeated cocaine treatment decreases whole-cell calcium current in rat nucleus accumbens neurons. J Pharmacol Exp Ther 301: 1119-1125.

Zhang XF, Hu XT, White FJ (1998). Whole-cell plasticity in cocaine withdrawal: reduced sodium currents in nucleus accumbens neurons. J Neurosci 18: 488-498. 